NISTIR 7336

\title{
Influence of Concentration and Additives on R123/Paraffinic Material Oil Boiling Heat Transfer Performance
}

\author{
Mark A. Kedzierski
}

D.H. Han

National Institute of Standards and Technology 



\title{
Influence of Concentration and Additives on R123/Paraffinic Material Oil Boiling Heat Transfer Performance
}

\author{
Mark A. Kedzierski \\ U.S DEPARTMENT OF COMMERCE \\ National Institute of Standard and Technology \\ Building Environment Division \\ Building and Fire Research Laboratory \\ Gaithersburg, MD 20899-8631
}

\section{D.H. Han}

Institute of Advanced Machinery Design

Korea University, 136-701

Seoul, Korea

September 2006

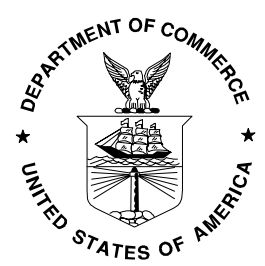

U.S. Department of Commerce Carlos M. Gutierrez, Secretary 



\title{
Influence of Additives and Concentration on R123/Paraffinic Mineral Oil Pool Boiling Heat Transfer
}

\author{
M. A. Kedzierski \\ National Institute of Standards and Technology \\ Bldg. 226, Rm B114 \\ Gaithersburg, MD 20899 \\ Phone: (301) 975-5282 \\ Fax: (301) 975-8973 \\ D.H. Han \\ Institute of Advanced Machinery Design \\ Korea University, 136-701 \\ Seoul, Korea
}

\begin{abstract}
This report investigates the effect that oil concentration had on the boiling performance of an R123/paraffinic mineral oil mixture on a roughened, horizontal flat surface. For all compositions $(0.5 \%, 1 \%$, and $2 \%)$, the lubricant caused a heat transfer degradation relative to the heat transfer of pure R123 of between $2 \%$ and $70 \%$ for the range of measured heat fluxes. The heat transfer degradation was shown to increase with lubricant mass fraction. The minimum heat transfer degradation for each mixture ranged between $2 \%$ and $12 \%$ and occurred at approximately $20 \mathrm{~kW} / \mathrm{m}^{2}$. For a given composition, the heat transfer degradation increased as the heat flux increased from roughly $20 \mathrm{~kW} / \mathrm{m}^{2}$ to $90 \mathrm{~kW} / \mathrm{m}^{2}$. In addition, the effect of two trial additives on the pool boiling heat transfer of an R123/paraffinic mineral oil mixture was examined in order to test the validity of a theory for choosing oil additives to enhance boiling performance. The verification tests were inconclusive. More research with lubricants and additives with greater differences in surface tensions is required to develop a more rigorous and quantifiable theory for designing additives that improve boiling heat transfer.
\end{abstract}

Keywords: refrigerants, additives, boiling, enhanced heat transfer, refrigerant/lubricant mixtures, paraffinic mineral oil 


\section{TABLE OF CONTENTS}

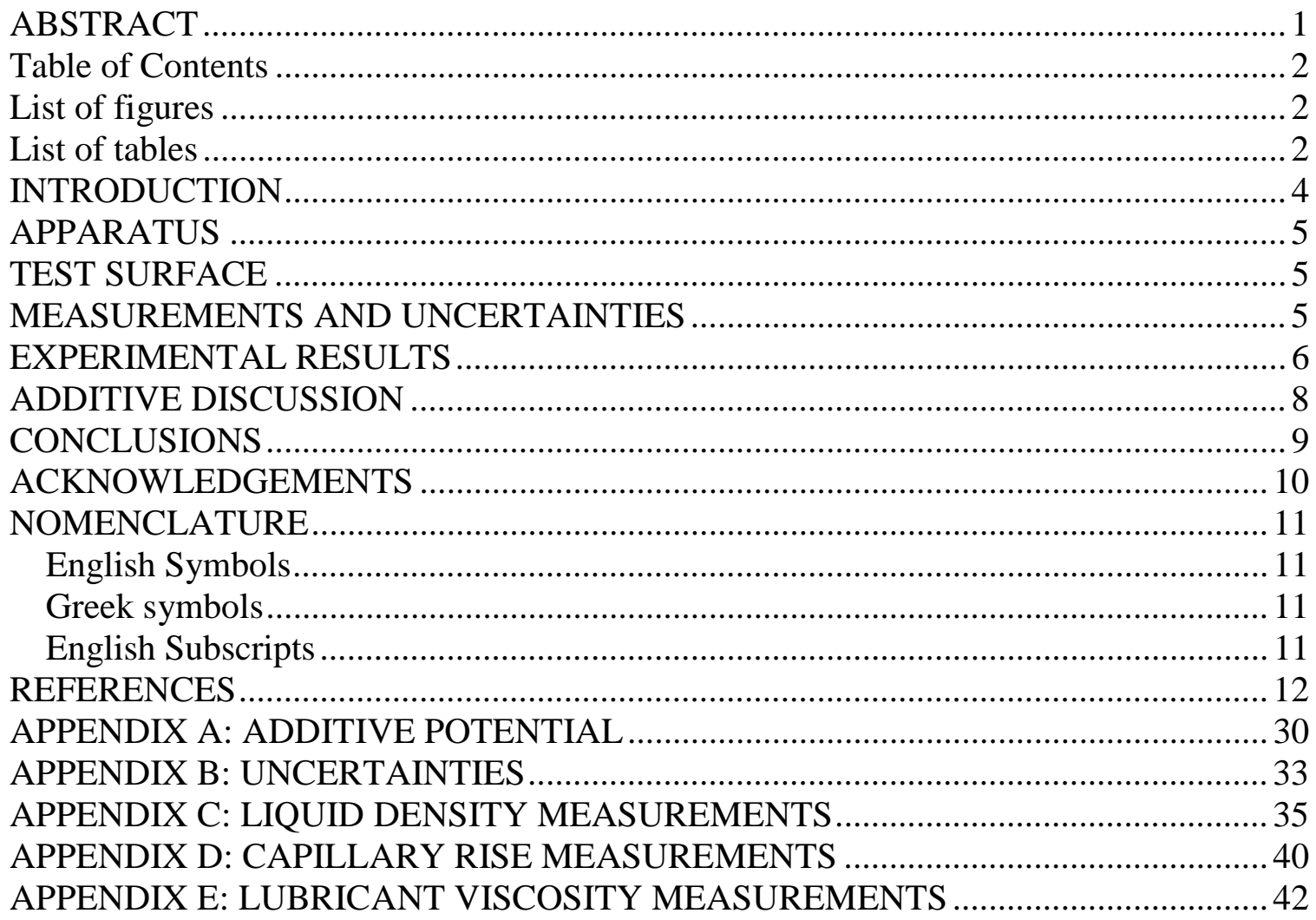

\section{LIST OF FIGURES}

Fig. 1 Schematic of test apparatus

Fig. 2 OFHC copper flat test plate with cross-hatched surface and thermocouple coordinate

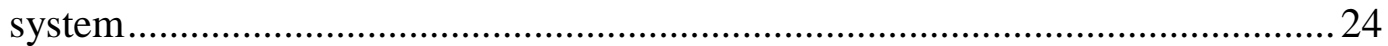

Fig. 3 Pure R123 boiling curve for plain surface …………………………………....2 25

Fig. 4 R134a /PARA mixtures boiling curves for plain surface ……..............................26

Fig. 5 R123/PARA/PG (97.8/2/0.2) boiling curve for plain surface................................2 27

Fig. 6 R123/PARA/LP1 (97.8/2/0.2) boiling curve for plain surface .............................. 28

Fig. 7 R123/PARA mixture heat fluxes relative to that of pure R123 for a plain surface29

Fig. 8 R123/PARA/PG (97.8/2/0.2) and R123/PARA/LP1 (97.8/2/0.2) mixture heat fluxes relative to that of the R123/PARA (98/2) mixture for a plain surface................... 30

Fig. A.1 Efficiency of centrifugal chillers at industry rating conditions (Fischer et al., 1994)

Fig. A.2 R11 water chiller COP improvement for a given evaporator enhancement ......33

Fig. B.1 Expanded relative uncertainty in the heat flux of the surface at the $95 \%$ confidence

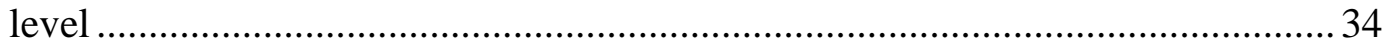

Fig. B.2 Expanded uncertainty in the temperature of the surface at the $95 \%$ confidence level

\section{LIST OF TABLES}


Table 1 Base lubricant and additive properties ................................................... 13

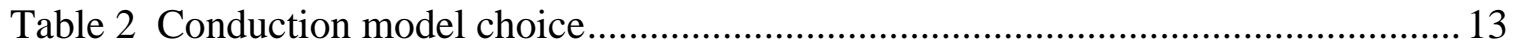

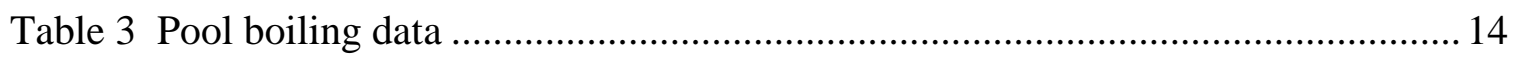

Table 4 Number of test days and data points ........................................................... 19

Table 5 Estimated parameters for cubic boiling curve fits for plain copper surface ....... 19

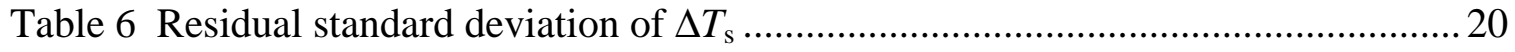

Table 7 Average magnitude of $95 \%$ multi-use confidence interval for mean $T_{\mathrm{w}}-T_{\mathrm{s}}(\mathrm{K}) .21$

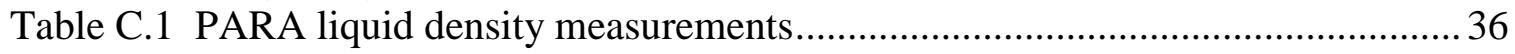

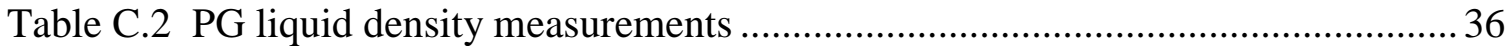

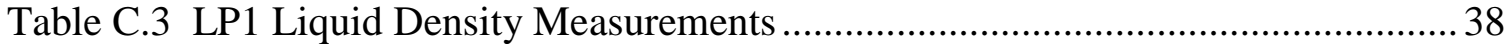

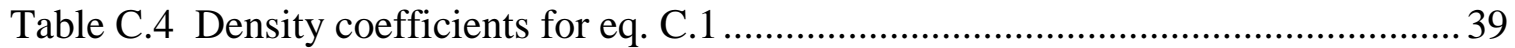

Table D.1 Capillary rise measurements for LP1 ....................................................... 41

Table D.2 Capillary rise measurements for PG........................................................... 41

Table D.3 Capillary rise measurements for PARA ........................................................ 41

Table E.1 Kinematic viscosity measurements for PARA .......................................... 42

Table E.2 Kinematic viscosity measurements for PG ............................................ 42

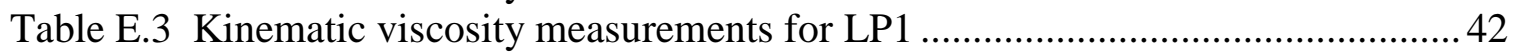




\section{INTRODUCTION}

The quest for understanding how lubricants and lubricant additives influence pool boiling has always been important in terms of how lubricants affect the design of efficient, affordable and reliable equipment. Improving the efficiency of existing air-conditioning equipment has been significantly emphasized with the recent blackout of the U.S. Northeast and escalating energy and copper costs. Increased accuracy in the sizing of evaporators affords the opportunity for using less copper in evaporators. Consequently, every trustworthy refrigerant/lubricant pool boiling heat transfer measurement can contribute to the pursuit of a fundamental boiling model. In addition, as illustrated in Appendix A, a refrigerant oil additive that improves water chiller efficiency could be a cost-effective and immediate means of reducing operating costs and improving the reliability of (reduced demand on) our nation's electricity grid. Because of this, agencies in the US federal government have been interested in the possibility of using additives to improve chiller performance. Toward this end, NIST ${ }^{1}$ (Kedzierski, $2004 \& 2006$ ) has proposed a theory with a purpose of selecting lubricants that when added to the base lubricant of an existing chiller will improve the pool boiling performance.

As shown by Kedzierski (2001c), the viscosity, miscibility and concentration of the lubricant strongly influence refrigerant/lubricant pool boiling. The properties of the lubricant closest to the wall essentially control the boiling. Consequently, if an additive (or added lubricant) is to have an impact on a given refrigerant/lubricant system, there would be a greater likelihood for influence if the additive can exist as a monolayer on the surface. If the additive is wellmixed in the lubricant excess layer (which is likely for a chemically similar additive and lubricant), it will have minimal influence on the heat transfer if it is only $2 \%$ by mass of the lubricant (typical additive charge). For this reason, two of the three basic rules for an additive to potentially enhance boiling heat transfer, according to the NIST hypothesis, are concerned with determining if a monolayer forms or not. According to the theory, the two requirements for a monolayer to form are: (1) the liquid-vapor surface tension of the additive should be larger than that of the base lubricant, and (2) the base lubricant and the additive must be "chemically dissimilar." At this point in time, these rules are not well defined. For example, it is not known how large of a difference between surface-tensions is required. In addition, synthetic lubricant and mineral oil are sufficiently different to satisfy the "chemically dissimilar" definition, but this may not be true for all cases. The third and final rule for enhancement is that the viscosity of the additive must be larger than that of the base lubricant. However, an additive with larger viscosity than the base lubricant will potentially induce an enhancement in boiling heat transfer only if it forms a monolayer. In other words, all three rules or conditions must be satisfied before a lubricant can have the potential of being an effective additive.

The primary goals of this study were to (1) attempt to verify or disprove the NIST rules for selecting lubricants to improve pool boiling heat transfer, and (2) to contribute R123/lubricant pool boiling data to the literature in support of improved boiling modeling. The base lubricant chosen for use with R123 was a paraffinic mineral oil with a nominal kinematic viscosity of $85 \mu \mathrm{m}^{2} / \mathrm{s}$ at $297.8 \mathrm{~K}$. Paraffinic oils are typically used for ammonia applications and less typically with other low pressure refrigerants like R123. The primary

\footnotetext{
${ }^{1}$ NIST (National Institute of Standards and Technology) is part of the U.S. Department of Commerce.
} 
reason for the selection of this particular paraffinic mineral was because it had the smallest liquid-vapor surface tension with a room temperature viscosity larger than $60 \mu \mathrm{m}^{2} / \mathrm{s}$ of all lubricants that were found in an extensive search of various mineral oils. By choosing a base lubricant with a small surface tension and a large viscosity, the opportunity for finding additives to enhance the boiling performance was improved. Following the NIST additive rules for enhancing pool boiling heat transfer, two synthetic oils were chosen (PG and LP1) as additives that had both larger viscosity and larger surface tension than the paraffinic base lubricant. Table 1 shows that the viscosity of the two oils that were used as additives were approximately 150 $\mu \mathrm{m}^{2} / \mathrm{s}$ and $2000 \mu \mathrm{m}^{2} / \mathrm{s}$ at $297.8 \mathrm{~K}$ for PG and LP1, respectively. Also shown in Table 1 is that the surface tensions are only nominally $5 \%$ larger than that of the paraffinic $\left(30.6 \mu \mathrm{m}^{2} / \mathrm{s} \pm 0\right.$. $\left.7 \mu \mathrm{m}^{2} / \mathrm{s}\right)$.

\section{APPARATUS}

Figure 1 shows a schematic of the apparatus that was used to measure the pool boiling data of this study. More specifically, the apparatus was used to measure the liquid saturation temperature $\left(T_{\mathrm{s}}\right)$, the average pool-boiling heat flux $\left(q^{\prime \prime}\right)$, and the wall temperature $\left(T_{\mathrm{w}}\right)$ of the test surface. The three principal components of the apparatus were the test chamber, the condenser, and the purger. The internal dimensions of the test chamber were $25.4 \mathrm{~mm} \times 257$ $\mathrm{mm} \times 1.54 \mathrm{~m}$. The test chamber was charged with approximately $7 \mathrm{~kg}$ of refrigerant, giving a liquid height of approximately $80 \mathrm{~mm}$ above the test surface. As shown in Fig. 1, the test section was visible through two opposing, flat $150 \mathrm{~mm} \times 200 \mathrm{~mm}$ quartz windows. The bottom of the test surface was heated with high velocity $(2.5 \mathrm{~m} / \mathrm{s})$ water flow. The vapor produced by liquid boiling on the test surface was condensed by the brine-cooled, shell-andtube condenser and returned as liquid to the pool by gravity. Further details of the test apparatus can be found in Kedzierski (2002a) and Kedzierski (2001a).

\section{TEST SURFACE}

Figure 2 shows the oxygen-free high-conductivity (OFHC) copper flat test plate used in this study. The test plate was machined out of a single piece of OFHC copper by electric discharge machining (EDM). A tub grinder was used to finish the heat transfer surface of the test plate with a crosshatch pattern. Average roughness measurements were used to estimate the range of average cavity radii for the surface to be between $12 \mu \mathrm{m}$ and $35 \mu \mathrm{m}$. The relative standard uncertainty of the cavity measurements were approximately $\pm 12 \%$. Further information on the surface characterization can be found in Kedzierski (2001a).

\section{MEASUREMENTS AND UNCERTAINTIES}

The standard uncertainty $\left(u_{i}\right)$ is the positive square root of the estimated variance $u_{i}{ }^{2}$. The individual standard uncertainties are combined to obtain the expanded uncertainty $(U)$, which is calculated from the law of propagation of uncertainty with a coverage factor. All measurement uncertainties are reported at the $95 \%$ confidence level except where specified otherwise. For the sake of brevity, only an outline of the basic measurements and uncertainties is given below. Complete detail on the heat transfer measurement techniques and uncertainties can be found in Kedzierski (2000a) and Appendix B, respectively. 
All of the copper-constantan thermocouples and the data acquisition system were calibrated against a glass-rod standard platinum resistance thermometer (SPRT) and a reference voltage to a residual standard deviation of $0.005 \mathrm{~K}$. Considering the fluctuations in the saturation temperature during the test and the standard uncertainties in the calibration, the expanded uncertainty of the average saturation temperature was no greater than $0.04 \mathrm{~K}$. Consequently, it is believed that the expanded uncertainty of the temperature measurements was less than $0.1 \mathrm{~K}$.

Twenty $0.5 \mathrm{~mm}$ diameter thermocouples were force fitted into the wells of the side of the test plate shown in Fig. 2. The heat flux and the wall temperature were obtained by regressing the measured temperature distribution of the block to the governing two-dimensional conduction equation (Laplace equation). In other words, rather than using the boundary conditions to solve for the interior temperatures, the interior temperatures were used to solve for the boundary conditions following a backward stepwise procedure given in Kedzierski $(1995)^{2}$. Fourier's law and the fitted constants from the Laplace equation were used to calculate the average heat flux $\left(q^{\prime \prime}\right)$ normal to and evaluated at the heat transfer surface based on its projected area. The average wall temperature $\left(T_{\mathrm{w}}\right)$ was calculated by integrating the local wall temperature $(T)$. The wall superheat was calculated from $T_{\mathrm{w}}$ and the measured temperature of the saturated liquid $\left(T_{\mathrm{s}}\right)$. Considering this, the relative expanded uncertainty in the heat flux $\left(U_{q^{\prime \prime}}\right)$ was greatest at the lowest heat fluxes, approaching $10 \%$ of the measurement near $10 \mathrm{~kW} / \mathrm{m}^{2}$. In general, the $U_{q^{\prime \prime}}$ remained approximately within $3 \%$ and 6 $\%$ for heat fluxes greater than $30 \mathrm{~kW} / \mathrm{m}^{2}$. The average random error in the wall superheat $\left(U_{\mathrm{Tw}}\right)$ was between $0.04 \mathrm{~K}$ and $0.1 \mathrm{~K}$. Plots of $U_{q^{\prime \prime}}$ and $U_{\mathrm{Tw}}$ versus heat flux can be found in Appendix B.

\section{EXPERIMENTAL RESULTS}

The heat flux was varied roughly between $10 \mathrm{~kW} / \mathrm{m}^{2}$ and $100 \mathrm{~kW} / \mathrm{m}^{2}$ to simulate a range of possible operating conditions for R123 chillers. All pool-boiling tests were taken at $277.6 \mathrm{~K}$ saturated conditions. The data were recorded consecutively starting at the largest heat flux and descending in intervals of approximately $4 \mathrm{~kW} / \mathrm{m}^{2}$. The descending heat flux procedure minimized the possibility of any hysteresis effects on the data, which would have made the data sensitive to the initial operating conditions. Table 3 presents the measured heat flux and wall superheat for all the data of this study. Table 4 gives the number of test days and data points for each fluid.

The mixtures were prepared by charging the test chamber (see Fig. 1) with pure R123 to a known mass. Next, a measured mass of lubricant was injected with a syringe through a port in the test chamber. The refrigerant/lubricant solution was mixed by flushing pure refrigerant through the same port where the lubricant was injected. After the tests with the refrigerant/lubricant mixture were completed, the additive was added to the existing test chamber charge in the same manner as for the lubricant. Additives were added to the refrigerant/lubricant (98/2) mixture as roughly $10 \%$ of the existing mass of lubricant in the system giving an R123/PARA/ PG (97.8/2/0.2) mixture and an R123/PARA/LP1 (97.8/2/0.2) mixture. All compositions were determined from the masses of the charged components and

\footnotetext{
${ }^{2}$ For the record, Table 2 provides functional forms of the Laplace equation that were used in this study in the same way as was done in Kedzierski (1995) and in similar studies by this author.
} 
are given on a mass fraction percent basis. The maximum uncertainty of the composition measurement is approximately $0.02 \%$, e.g., the range of a $2.0 \%$ composition is between $1.98 \%$ and $2.02 \%$. Nominal or target mass compositions are used in the discussion. For example, the "actual" mass composition of the PARA in the R123/PARA (99.5/0.5) mixture was $0.54 \% \pm 0.02 \%$. Likewise, the PARA mass fractions for R123/PARA (99/1) and the R123/PARA (98/2) mixtures were $0.98 \% \pm 0.02 \%$ and $1.99 \% \pm 0.02 \%$, respectively. Using the same uncertainties, the additive mixtures as tested were R123/PARA/ PG (97.90/1.97/0.13) and R123/PARA/LP1 (97.87/1.94/0.19).

Figure 3 is a plot of the measured heat flux $\left(q^{\prime \prime}\right)$ versus the measured wall superheat $\left(T_{\mathrm{w}}-T_{\mathrm{s}}\right)$ for pure R123 at a saturation temperature of $277.6 \mathrm{~K}$. The opened circles represent six days of boiling measurements made over a period of approximately one week. The solid lines shown in Fig. 3 are cubic best-fit regressions or estimated means of the data. Three of the 107 measurements were removed before fitting because they were identified as "outliers" based on having both high influence and high-leverage (Belsley et al., 1980). Table 5 gives the constants for the cubic regression of the superheat versus the heat flux for all of the fluids tested here. The residual standard deviation of the regressions - representing the proximity of the data to the mean - are given in Table 6 . The dashed lines to either side of the mean represent the lower and upper $95 \%$ simultaneous (multiple-use) confidence intervals for the mean. From the confidence intervals, the expanded uncertainty of the estimated mean wall superheat was $0.26 \mathrm{~K}$ and $0.04 \mathrm{~K}$ for superheats less than and greater than $14.5 \mathrm{~K}$, respectively. Table 7 provides the average magnitude of $95 \%$ multi-use confidence interval for the fitted wall superheat for all of the test data.

Figure 4 plots the measured heat flux $\left(q^{\prime \prime}\right)$ versus the measured wall superheat $\left(T_{\mathrm{w}}-T_{\mathrm{s}}\right)$ at a saturation temperature of $277.6 \mathrm{~K}$ for the three R123/PARA mixtures. Comparison of the three boiling curves shows that they are within $2 \mathrm{~kW} / \mathrm{m}^{2}$ of each other and the pure R123 performance at a superheat of approximately $11 \mathrm{~K}$. For mean superheats greater than $11 \mathrm{~K}$, the boiling heat transfer degradation with respect to pure R123 boiling heat transfer increases with increasing lubricant concentration. This is an expected trend as outlined in Kedzierski (2001c) because the bubble size becomes smaller for increasing lubricant mass fraction, which leads to a reduction in heat transfer if the site density does not increase enough to compensate for the loss of vapor generation per bubble.

Figure 5 is a plot of the measured heat flux $\left(q^{\prime \prime}\right)$ versus the measured wall superheat $\left(T_{\mathrm{w}}-T_{\mathrm{s}}\right)$ for the R123/PARA/PG (97.8/2/0.2) mixture at a saturation temperature of $277.6 \mathrm{~K}$. The open diamonds represent over 50 boiling measurements made over three consecutive days. For comparison, the mean of the R123/PARA (98/2) mixture boiling curve is provided as a coarsely dashed, gray line. The average expanded uncertainty of the estimated mean wall superheat for superheats greater and less than $15.5 \mathrm{~K}$ was $0.14 \mathrm{~K}$ and $0.46 \mathrm{~K}$, respectively.

Figure 6 is a plot of the measured heat flux $\left(q^{\prime \prime}\right)$ versus the measured wall superheat $\left(T_{\mathrm{w}}-T_{\mathrm{s}}\right)$ for the R123/PARA/LP1 (97.8/2/0.2) mixture at a saturation temperature of $277.6 \mathrm{~K}$. The open stars represent 126 boiling measurements made over four days within a week. For comparison, the mean of the R123/PARA (98/2) mixture boiling curve is provided as a coarsely dashed, gray line. The average expanded uncertainty of the estimated mean wall superheat for superheats greater and less than $15.5 \mathrm{~K}$ was $0.11 \mathrm{~K}$ and $0.31 \mathrm{~K}$, respectively. 
A more detailed comparison of the R123/PARA and the R123/PARA/additive heat transfer performances the relative to R123 and R123/PARA (98/2), respectively, is given in Figs. 7 and 8. Figure 7 plots the ratio of the R123/PARA mixture heat flux to the pure R123 heat flux $\left(q^{\prime \prime} q^{\prime \prime}\right)$ versus the pure R123 heat flux $\left(q_{\mathrm{p}}^{\prime \prime}\right)$ at the same wall superheat. Figure 7 illustrates the influence of lubricant mass composition on the R123/PARA boiling curve with solid lines representing the mean heat flux ratios for each mixture. Overall, lubricant for all compositions has caused a heat transfer degradation relative to the heat transfer of pure R123 for all measured heat fluxes. The degradation is shown to increase with lubricant mass fraction. For example, the average heat flux ratio for the R123/PARA (99.5/0.5), the R123/PARA (99/1), and the R123/PARA (98/2) mixture from approximately $15 \mathrm{~kW} / \mathrm{m}^{2}$ to $100 \mathrm{~kW} / \mathrm{m}^{2}$ was $0.64,0.55$, and 0.48 , respectively. The minimum heat transfer degradation for each mixture (or the maximum heat transfer) is shown on Fig. 7 to be at approximately $20 \mathrm{~kW} / \mathrm{m}^{2}$. For $20 \mathrm{~kW} / \mathrm{m}^{2}$, the heat flux ratio for the R123/PARA $(99.5 / 0.5)$, the R123/PARA (99/1), and the R123/PARA (98/2) mixture is $0.98 \pm 0.02,0.90 \pm 0.025$, and $0.88 \pm 0.02$, respectively. The lubricant effect becomes more pronounced as the heat flux increases from roughly $20 \mathrm{~kW} / \mathrm{m}^{2}$ to $90 \mathrm{~kW} / \mathrm{m}^{2}$ producing heat flux ratios of approximately $0.52,0.4$, and 0.3 at $90 \mathrm{~kW} / \mathrm{m}^{2}$ for the R123/PARA (99.5/0.5), the R123/PARA (99/1), and the R123/PARA (98/2) mixtures, respectively.

Figure 8 details the effect that the additives had on the R123/PARA (98/2) boiling curve. The figure plots the ratio of the R123/PARA/PG (97.8/2/0.2) heat flux to the R123/PARA $(98 / 2)$ heat flux $\left(q^{\prime \prime}{ }_{\mathrm{m}} / q^{\prime \prime}{ }_{2 \%}\right)$ versus the R123/PARA $(98 / 2)$ mixture heat flux $\left(q^{\prime \prime}{ }_{2 \%}\right)$ at the same wall superheat. Likewise, the R123/PARA/LP1 (97.8/2/0.2) heat flux to the R123/PARA (98/2) heat flux $\left(q^{\prime \prime}{ }_{\mathrm{m}} / q^{\prime \prime}{ }_{2 \%}\right)$ versus the R123/PARA $(98 / 2)$ mixture heat flux $\left(q^{\prime \prime}{ }_{2 \%}\right)$ at the same wall superheat is also plotted. A heat transfer enhancement exists where the heat flux ratio is greater than one and the $95 \%$ simultaneous confidence intervals (depicted by the shaded regions) do not include the value one. Figure 8 shows that for heat fluxes less than $85 \mathrm{~kW} / \mathrm{m}^{2}$, neither additive causes an enhancement of R123/PARA (98/2) pool boiling heat transfer. For the most part, either a degradation or no measurable difference is observed compared to the R123/PARA (98/2) mixture. A small $5 \%$ enhancement of the heat flux is obtained for the R123/PARA/LP1 (97.8/2/0.2) mixture at a heat flux of approximately $90 \mathrm{~kW} / \mathrm{m}^{2}$. Similarly, the R123/PARA/PG (97.8/2/0.2) mixture shows a maximum heat flux ratio of 1.03 at a heat flux of approximately $27 \mathrm{~kW} / \mathrm{m}^{2}$. However, because the confidence intervals include the value of one at the maximum, no difference between the mixture/additive performance and that of the mixture can be established. Overall, the average heat flux ratio for the R123/PARA/LP1 (97.8/2/0.2) mixture from approximately $7 \mathrm{~kW} / \mathrm{m}^{2}$ to $89 \mathrm{~kW} / \mathrm{m}^{2}$ was 0.95 . Likewise, the average heat flux ratio for the R123/PARA/PG (97.8/2/0.2) mixture from approximately $9 \mathrm{~kW} / \mathrm{m}^{2}$ to 81 $\mathrm{kW} / \mathrm{m}^{2}$ was 0.97 .

\section{ADDITIVE DISCUSSION}

The heat transfer results summarized in Fig. 8, for the most part, show that the lubricants chosen as additives had little or no effect on the boiling performance of the R123/mineral oil (98/2) system. However, considering that the rules provided by the NIST additive hypothesis are not precisely quantified, the preceding heat transfer results cannot be used to prove or disprove the basic premise of the hypothesis. The main reason for this is that it cannot be 
known if the surface-tension difference between the additive and the base lubricant was sufficient enough to cause the formation of an additive monolayer. As Table 1 shows, the differences in the mean kinematic viscosity appears to be significant enough and with satisfactorily small uncertainties for a viscosity effect to be present. However, the surfacetension differences between the base lubricant and the additives are marginal at best. In fact, the LP1 lubricant exhibits nearly no difference in surface tension between it and the PARA $(1.1 \mathrm{mN} / \mathrm{m} \pm 1 \mathrm{mN} / \mathrm{m})$ when the measurement uncertainties are taken into consideration. As a result, when considering LP1 as a potential additive, the evidence is not sufficient to suggest that the surface tension difference was significant enough for the LP1 to form a monolayer at the surface. Consequently, if a monolayer is not formed, then the benefits of a larger viscosity cannot be realized because LP1 is only $10 \%$ of the mass of the base lubricant. ${ }^{3}$ Also, although the positive difference in surface tension between PG and the base lubricant is statistically significant $(1.6 \mathrm{mN} / \mathrm{m} \pm 1 \mathrm{mN} / \mathrm{m})$, the difference may not be large enough. There may be a critical difference in surface tensions that must be attained before a monolayer a can be formed. In support of this, when Kedzierski (2004) observed a heat transfer enhancement with additives, there was an accompanying difference in surface tension of $3 \mathrm{mN} / \mathrm{m} \pm 1.4 \mathrm{mN} / \mathrm{m}$, which is approximately $88 \%$ larger than the surface tension difference between the present base mineral oil and PG.

Future research is required to investigate the influence of the magnitude of the surfacetension difference on boiling heat transfer performance. In addition, there may be other primary lubricant property effects that govern an additive's influence on boiling other than surface tension, viscosity, and chemical similarity with the base lubricant. For example, additive polarity and miscibility may play more of a primary role along with heat transfer. In other words, how the thermal boundary layer interacts with the excess layer and its properties should be studied. Further investigation into the above effects may lead to a more rigorous and quantifiable theory that can be used to develop additives that improve boiling heat transfer for the benefit of the refrigeration and air-conditioning industry.

\section{CONCLUSIONS}

The effect of paraffinic mineral oil concentration on the boiling performance of R123/paraffinic mineral oil mixtures on a roughened, horizontal flat surface was investigated. For all compositions, the lubricant caused a heat transfer degradation relative to the heat transfer of pure R123 for all measured heat fluxes. The heat transfer degradation was shown to increase with lubricant mass fraction. The minimum heat transfer degradation for each mixture occurred at approximately $20 \mathrm{~kW} / \mathrm{m}^{2}$. For a given composition, the heat transfer degradation increased as the heat flux increases from roughly $20 \mathrm{~kW} / \mathrm{m}^{2}$ to $90 \mathrm{~kW} / \mathrm{m}^{2}$.

The effect of two trial additives on the pool boiling heat transfer of an R123/paraffinic mineral oil mixture was examined in order to test the validity of a theory for choosing oil additives to enhance boiling performance. In general, the specific lubricants chosen as additives had little or no effect on the boiling performance of the R123/mineral oil mixture.

\footnotetext{
${ }^{3}$ In addition, the Kedzierski (2001) showed a linear heat transfer enhancement with respect to increasing viscosity only between roughly $5 \mathrm{cSt}$ and $200 \mathrm{cSt}$. Consequently, extrapolation of the effect of a $2000 \mathrm{cSt}$ on heat transfer is not justified. In other words, a heat transfer maximum may exist with respect to viscosity for some viscosity greater than $200 \mathrm{cSt}$.
} 
However, because the rules provided by the NIST additive theory are not precisely quantified, the heat transfer results could not be used to prove or disprove the basic premise of the hypothesis. The main reason for this is that it is not known if the surface-tension difference between the additive and the base lubricant was sufficient enough to cause the formation of an additive monolayer. Future research with greater differences in surface tensions is required to investigate the influence of the magnitude of the surface-tension difference on boiling heat transfer performance in order to develop a more rigorous and quantifiable theory that can be used to design additives that improve boiling heat transfer.

\section{ACKNOWLEDGEMENTS}

This work was funded by NIST. Thanks go to the following NIST personnel for their constructive criticism of the first draft of the manuscript: Dr. S. Treado, and Dr. P.

Domanski. Thanks goes to the N. Sawant of the Catholic University of America for his constructive criticism of the second draft of the manuscript. Furthermore, the authors extend appreciation to W. Guthrie and Mr. A. Heckert of the NIST Statistical Engineering Division for their consultations on the uncertainty analysis. The lubricant property measurements were made by Dr. M. Gong of the Chinese Academy of Sciences while he was a Guest Researcher at NIST. Both the PG (EMKAROX DGLF118) and the LP1 (Hypermer LP1, a polycondensed fatty acid separated from its solid phase at room temperature) were donated by Dr. S. Randles of Uniqema and were much appreciated. 


\section{NOMENCLATURE}

\section{English Symbols}

$A_{\mathrm{n}} \quad$ regression constant in Table $5 \mathrm{n}=0,1,2,3$

$C_{\mathrm{o}} \quad$ viscometer calibration constant, $\mu \mathrm{m}^{2} \mathrm{~s}^{-1}$

COP Coefficient of Performance

$d \quad$ liquid pool height, $\mathrm{m}$

$E_{\mathrm{COP}}$ percent increase in COP

$E_{\mathrm{h}} \quad$ percent increase in $h$

$\mathrm{g} \quad$ gravitational acceleration, $\mathrm{m} \mathrm{s}^{-2}$

$h$ heat transfer coefficient, $\mathrm{W} \mathrm{K}^{-1} \mathrm{~m}^{-2}$

$l \quad$ capillary rise height, $\mathrm{m}$

$L_{\mathrm{y}} \quad$ length of test surface (Fig. 2), m

LMTD Log-Mean-Temperature-Difference, K

$P \quad$ vapor pressure, $\mathrm{kPa}$

$q^{\prime \prime} \quad$ average wall heat flux, $\mathrm{W} \mathrm{m}^{-2}$

$r$ radius of capillary tube, $\mathrm{m}$

$T$ temperature, $\mathrm{K}$

$T_{\mathrm{w}} \quad$ temperature at roughened surface, $\mathrm{K}$

$U$ expanded uncertainty

$u_{\mathrm{i}} \quad$ standard uncertainty

$X \quad$ model terms given in Table 2

Greek symbols

$\Delta T \quad$ temperature difference, $\mathrm{K}$

$\Delta T_{\mathrm{s}} \quad$ wall superheat: $T_{\mathrm{w}}-T_{\mathrm{s}}, \mathrm{K}$

$\Delta v \quad$ difference between base lubricant and additive kinematic viscosity, $\mathrm{m}^{2} \mathrm{~s}^{-1}$

$\Delta \rho \quad$ difference between liquid and vapor density, $\mathrm{kg} \mathrm{m}^{-3}$

$\Delta \sigma \quad$ difference between base lubricant and additive surface tension, $\mathrm{kg} \mathrm{s}^{-2}$

$v \quad$ kinematic viscosity, $\mathrm{m}^{2} \mathrm{~s}^{-1}$

$\sigma \quad$ surface tension, $\mathrm{kg} \mathrm{s}^{-2}$

\begin{tabular}{ll}
\multicolumn{2}{l}{ English Subscripts } \\
$\mathrm{B}$ & baseline \\
$\mathrm{Bc}$ & condenser baseline \\
$\mathrm{Be}$ & evaporator baseline \\
$\mathrm{c}$ & condenser \\
$\mathrm{e}$ & evaporator \\
$\mathrm{m}$ & mixture \\
$\mathrm{p}$ & pure R123 \\
$\mathrm{q} "$ & heat flux \\
$\mathrm{r}$ & refrigerant-side \\
$\mathrm{s}$ & saturated state \\
$\mathrm{Tw}$ & wall temperature \\
$\mathrm{V}$ & vapor \\
$\mathrm{W}$ & wall or water-side \\
$2 \%$ & R123/PARA $(98 / 2)$
\end{tabular}




\section{REFERENCES}

Adamson, A. W., and Gast, A. P., 1997, Physical Chemistry of Surfaces, Interscience Publ., New York, 6th Ed., p. 11.

Belsley, D. A., Kuh, E., and Welsch, R. E., 1980, Regression Diagnostics: Identifying Influential Data and Sources of Collinearity, New York: Wiley.

Fischer, S. K, Tomlinson, J. J., and Hughes, T. J., 1994, "Energy and Global Warming Impact of Not-in-kind and Next Generation CFC and HCFC Alternatives," US DOE and Alternative Fluorocarbons Environmental Acceptability Study (AFEAS) report, Washington, DC.

Incropera, F. P., and DeWitt, D. P., 1985, Fundamentals of Heat and Mass Transfer, 2nd ed., John Wiley \& Sons, New York.

Kedzierski, M. A., 2006, "Effect of Refrigerant Oil Additive on R134a and R123 Boiling Heat Transfer Performance," accepted for Int. J. Refrigeration.

Kedzierski, M. A, 2004, "Effect of Refrigerant Oil Additive on R134a and R123 Boiling Heat Transfer Performance and Related Issues for GSA," NISTIR 7132, U.S. Department of Commerce, Washington, D.C.

Kedzierski, M. A., 2002a, "Use of Fluorescence to Measure the Lubricant Excess Surface Density During Pool Boiling,” Int. J. Refrigeration, Vol. 25, pp.1110-1122.

Kedzierski, M. A., 2001a, "Use of Fluorescence to Measure the Lubricant Excess Surface Density During Pool Boiling," NISTIR 6727, U.S. Department of Commerce, Washington, D.C.

Kedzierski, M. A., 2001c, "The Effect of Lubricant Concentration, Miscibility and Viscosity on R134a Pool Boiling” Int. J. Refrigeration, Vol. 24, No. 4., pp. 348-366.

Kedzierski, M. A., 2000a, "Enhancement of R123 Pool Boiling by the Addition of Hydrocarbons," Int. J. Refrigeration, Vol. 23, pp. 89-100.

Kedzierski, M. A., 2000b, "The Effect of a Boiling Additive on R123 Condensation on a Vertical Integral-Fin Surface,” Int. J. Refrigeration, Vol. 23, pp. 101-111.

Kedzierski, M. A., 1995, "Calorimetric and Visual Measurements of R123 Pool Boiling on Four Enhanced Surfaces," NISTIR 5732, U.S. Department of Commerce, Washington. 
Table 1 Base lubricant and additive properties ${ }^{4}$

\begin{tabular}{|c|c|c|c|c|c|}
\hline \multicolumn{6}{|c|}{$T=297.8 \mathrm{~K}$} \\
\hline Lubricant & $v\left(\mu \mathrm{m}^{2} / \mathrm{s}\right)$ & $\Delta v\left(\mu \mathrm{m}^{2} / \mathrm{s}\right)$ & $\sigma(\mathrm{mN} / \mathrm{m})$ & $\Delta \sigma(\mathrm{mN} / \mathrm{m})$ & $\rho\left(\mathrm{kg} / \mathrm{m}^{3}\right)$ \\
\hline $\begin{array}{c}\text { Paraffinic } \\
\text { Mineral oil } \\
\text { (PARA) }\end{array}$ & $85 \pm 1.5$ & 0 & $30.6 \pm 0.7$ & 0 & 877 \\
\hline $\begin{array}{c}\text { DGLF118 } \\
\text { (PG) }\end{array}$ & $150.3 \pm 0.8$ & $65 \pm 1.8$ & $32.2 \pm 0.7$ & $1.6 \pm 1$ & 996 \\
\hline LP1 & $2000 \pm 500$ & $1915 \pm 500$ & $31.7 \pm 0.7$ & $1.1 \pm 1$ & 920 \\
\hline
\end{tabular}

Table 2 Conduction model choice

\begin{tabular}{|c|c|}
\hline \multicolumn{2}{|c|}{$\begin{array}{c}\mathrm{X}_{5}=\mathrm{y}\left(3 \mathrm{x}^{2}-\mathrm{y}^{2}\right) \quad \mathrm{X}_{6}= \\
\left.\mathrm{X}_{8}=\mathrm{yx}^{3}-\mathrm{yy}^{2}-\mathrm{x}^{2}\right) \quad \mathrm{X}_{7}=\mathrm{x}^{4}+\mathrm{y}^{4}-6\left(\mathrm{x}^{2}\right) \mathrm{y}^{2}\end{array}$} \\
\hline Fluid & Most frequent models \\
\hline $\begin{array}{c}\text { Pure R123 } \\
\text { (file: } p \text { R23ad.dat) }\end{array}$ & $\begin{array}{c}\mathrm{X}_{1}, \mathrm{X}_{5}(40 \text { of } 100) 40 \% \\
\mathrm{X}_{1}, \mathrm{X}_{2}, \mathrm{X}_{4}(38 \text { of } 100) 38 \% \\
\mathrm{X}_{1}, \mathrm{X}_{2}(9 \text { of } 100) 9 \%\end{array}$ \\
\hline $\begin{array}{l}\text { R123/PARA (99.5/0.5) } \\
\quad \text { (file: 5PARA.dat) }\end{array}$ & $\begin{array}{c}\mathrm{X}_{1}, \mathrm{X}_{2}, \mathrm{X}_{4}(42 \text { of } 88) 48 \% \\
\mathrm{X}_{1}, \mathrm{X}_{5}(18 \text { of } 88) 20 \% \\
\mathrm{X}_{1}, \mathrm{X}_{5}, \mathrm{X}_{6}(13 \text { of } 88) 15 \% \\
\end{array}$ \\
\hline $\begin{array}{l}\text { R123/PARA (99/1) } \\
\text { (file: PARA1.dat) }\end{array}$ & $\begin{array}{c}\mathrm{X}_{1}, \mathrm{X}_{2}, \mathrm{X}_{4}(46 \text { of } 84) 55 \% \\
\mathrm{X}_{1}, \mathrm{X}_{5}, \mathrm{X}_{6}(18 \text { of } 84) 21 \% \\
\mathrm{X}_{1}, \mathrm{X}_{2}, \mathrm{X}_{4}, \mathrm{X}_{6}(8 \text { of } 84) 9 \% \\
\mathrm{X}_{1}, \mathrm{X}_{2}, \mathrm{X}_{5}, \mathrm{X}_{6}(8 \text { of } 84) 9 \%\end{array}$ \\
\hline $\begin{array}{l}\text { R123/PARA (98/2) } \\
\text { (file: PARA2.dat) }\end{array}$ & $\begin{array}{c}\mathrm{X}_{1}, \mathrm{X}_{2}, \mathrm{X}_{4}(43 \text { of } 158) 27 \% \\
\mathrm{X}_{1}, \mathrm{X}_{2}(30 \text { of } 158) 19 \% \\
\mathrm{X}_{1}, \mathrm{X}_{2}, \mathrm{X}_{4}, \mathrm{X}_{6}(28 \text { of } 158) 18 \%\end{array}$ \\
\hline $\begin{array}{l}\text { R123/PARA/PG }(97.8 / 2 / 0.2) \\
\text { (file: PARAPG.dat) }\end{array}$ & $\begin{array}{c}\mathrm{X}_{1}, \mathrm{X}_{2}(13 \text { of } 52) 25 \% \\
\mathrm{X}_{1}, \mathrm{X}_{2}, \mathrm{X}_{4}(12 \text { of } 52) 23 \% \\
\mathrm{X}_{1}, \mathrm{X}_{2}, \mathrm{X}_{4}, \mathrm{X}_{6}(12 \text { of } 52) 23 \% \\
\end{array}$ \\
\hline $\begin{array}{l}\text { R123/PARA/LP1 }(97.8 / 2 / 0.2) \\
\text { (file: PARALP1.dat) }\end{array}$ & $\begin{array}{c}\mathrm{X}_{1}, \mathrm{X}_{2}(26 \text { of } 117) 22 \% \\
\mathrm{X}_{1}, \mathrm{X}_{2}, \mathrm{X}_{6}(26 \text { of } 117) 22 \% \\
\mathrm{X}_{1}, \mathrm{X}_{2}, \mathrm{X}_{4}, \mathrm{X}_{6}(25 \text { of } 117) 21 \%\end{array}$ \\
\hline
\end{tabular}

\footnotetext{
${ }^{4}$ Density, surface tension, and viscosity measurements and measurement methodologies are given in Appendixes C, D, and E, respectively.
} 
Table 3 Pool boiling data

Pure R123

File: PR123AD.dat

\begin{tabular}{|c|c|}
\hline$\Delta T_{\mathrm{s}}(\mathrm{K})$ & $q^{\prime \prime}\left(\mathrm{W} / \mathrm{m}^{2}\right)$ \\
\hline 16.17 & 100368.4 \\
\hline 15.45 & 78680.3 \\
\hline 15.12 & 67248.9 \\
\hline 14.77 & 56119.3 \\
\hline 14.30 & 37624.5 \\
\hline 13.95 & 31120.5 \\
\hline 12.47 & 22070.1 \\
\hline 10.76 & 16734.0 \\
\hline 8.58 & 14901.5 \\
\hline 16.64 & 112156.3 \\
\hline 16.18 & 98384.2 \\
\hline 15.92 & 90476.4 \\
\hline 15.51 & 76815.4 \\
\hline 15.13 & 64511.2 \\
\hline 14.81 & 54653.3 \\
\hline 14.55 & 43565.7 \\
\hline 13.95 & 31386.2 \\
\hline 12.56 & 22460.8 \\
\hline 16.35 & 103370.6 \\
\hline 16.23 & 100019.3 \\
\hline 16.08 & 96101.5 \\
\hline 15.80 & 88879.3 \\
\hline 15.63 & 84008.8 \\
\hline 15.48 & 78704.8 \\
\hline 15.33 & 73348.2 \\
\hline 15.21 & 69058.7 \\
\hline 15.09 & 64392.0 \\
\hline 14.99 & 60255.1 \\
\hline 14.86 & 55006.2 \\
\hline 14.70 & 48673.3 \\
\hline 14.58 & 44497.1 \\
\hline 14.38 & 38647.8 \\
\hline 14.26 & 36376.0 \\
\hline 14.04 & 32718.7 \\
\hline 13.79 & 29494.6 \\
\hline 13.23 & 25765.9 \\
\hline 12.78 & 23379.9 \\
\hline 12.22 & 21538.6 \\
\hline 11.67 & 19322.6 \\
\hline 10.98 & 17817.9 \\
\hline 10.25 & 16245.2 \\
\hline 9.40 & 15030.1 \\
\hline 8.33 & 14709.5 \\
\hline 7.68 & 13942.2 \\
\hline 16.37 & 102380.8 \\
\hline 15.93 & 91408.9 \\
\hline 15.50 & 75842.0 \\
\hline & \\
\hline
\end{tabular}

\begin{tabular}{|l|l|}
\hline 15.21 & 66140.9 \\
\hline 15.10 & 62536.8 \\
\hline 14.97 & 57355.2 \\
\hline
\end{tabular}$\quad$\begin{tabular}{|l|l|}
\hline 9.206 & 15759.4 \\
\hline 7.460 & 12867.5 \\
\hline
\end{tabular}

R123/PARA (99.5/0.5)

File: 5PARA.dat

\begin{tabular}{|l|l|}
\hline$\Delta T_{\mathrm{s}}(\mathrm{K})$ & $q^{\prime \prime}\left(\mathrm{W} / \mathrm{m}^{2}\right)$ \\
\hline 17.664 & 86194.2 \\
\hline 17.232 & 76725.6 \\
\hline 16.911 & 69740.7 \\
\hline 16.507 & 60527.9 \\
\hline 16.183 & 52047.5 \\
\hline 15.817 & 42105.5 \\
\hline 15.278 & 31945.6 \\
\hline 14.461 & 26278.3 \\
\hline 13.058 & 21748.3 \\
\hline 11.481 & 18073.6 \\
\hline 17.110 & 73547.5 \\
\hline 16.903 & 70136.6 \\
\hline 16.642 & 64810.8 \\
\hline 16.459 & 60912.1 \\
\hline 16.332 & 56797.3 \\
\hline 16.268 & 56529.1 \\
\hline 16.308 & 58731.8 \\
\hline 16.183 & 58840.4 \\
\hline 16.055 & 54914.5 \\
\hline 15.872 & 49986.0 \\
\hline 15.582 & 43960.3 \\
\hline 15.302 & 38495.0 \\
\hline 15.015 & 33827.9 \\
\hline 14.682 & 29441.2 \\
\hline 14.270 & 26576.7 \\
\hline 13.510 & 23877.1 \\
\hline 12.782 & 22250.2 \\
\hline 11.999 & 19818.2 \\
\hline 11.461 & 17850.9 \\
\hline 10.613 & 16655.9 \\
\hline 10.021 & 15740.2 \\
\hline 17.416 & 81537.8 \\
\hline 16.956 & 72659.9 \\
\hline 16.607 & 65639.2 \\
\hline 16.240 & 55665.9 \\
\hline 15.907 & 48123.2 \\
\hline 15.410 & 38185.6 \\
\hline 14.695 & 30002.1 \\
\hline 13.719 & 24581.0 \\
\hline 12.221 & 20327.8 \\
\hline 10.717 & 17344.8 \\
\hline 18.035 & 92753.1 \\
\hline 17.750 & 90300.5 \\
\hline 17.491 & 85067.9 \\
\hline 17.378 & 82792.4 \\
\hline & \\
\hline
\end{tabular}




\begin{tabular}{|l|l|}
\hline 17.25 & 79952.9 \\
\hline 16.96 & 75044.6 \\
\hline 16.75 & 70968.0 \\
\hline 16.58 & 67178.5 \\
\hline 16.39 & 62727.5 \\
\hline 16.26 & 58627.3 \\
\hline 15.94 & 51559.9 \\
\hline 15.68 & 46759.2 \\
\hline 15.46 & 41663.5 \\
\hline 15.25 & 37751.8 \\
\hline 14.91 & 32855.5 \\
\hline 14.52 & 29218.9 \\
\hline 14.11 & 26473.1 \\
\hline 13.76 & 24825.1 \\
\hline 12.87 & 22337.7 \\
\hline 12.15 & 20477.8 \\
\hline 11.50 & 18253.8 \\
\hline 10.72 & 16771.0 \\
\hline 9.92 & 15538.7 \\
\hline 17.85 & 90809.5 \\
\hline 17.65 & 85605.7 \\
\hline 17.44 & 82533.2 \\
\hline 17.24 & 78095.9 \\
\hline 17.00 & 73202.1 \\
\hline 16.85 & 70359.4 \\
\hline 16.63 & 65716.1 \\
\hline 16.46 & 61887.3 \\
\hline 16.32 & 56457.7 \\
\hline 16.14 & 52339.8 \\
\hline 15.89 & 47270.1 \\
\hline 15.73 & 43672.6 \\
\hline 15.38 & 35947.9 \\
\hline 15.13 & 32716.9 \\
\hline 14.57 & 28877.7 \\
\hline 14.16 & 26596.6 \\
\hline 13.61 & 24508.0 \\
\hline 12.90 & 22830.8 \\
\hline 12.12 & 20499.8 \\
\hline 11.28 & 17806.6 \\
\hline 10.87 & 17195.3 \\
\hline 9.76 & 15340.7 \\
\hline 8.91 & 15609.1 \\
\hline 8.26 & 14183.3 \\
\hline & \\
\hline
\end{tabular}

R123/PARA (99/1) File: PARA1.dat

\begin{tabular}{|l|c|}
\hline$\Delta T_{\mathrm{s}}(\mathrm{K})$ & $q^{\prime \prime}\left(\mathrm{W} / \mathrm{m}^{2}\right)$ \\
\hline 17.68 & 75831.4 \\
\hline 17.63 & 71742.8 \\
\hline 17.35 & 69074.2 \\
\hline 17.13 & 62849.3 \\
\hline 16.95 & 58990.7 \\
\hline
\end{tabular}

\begin{tabular}{|l|l|}
\hline 16.78 & 55396.2 \\
\hline 16.51 & 50041.3 \\
\hline 16.23 & 43677.3 \\
\hline 16.03 & 39797.6 \\
\hline 15.74 & 35256.6 \\
\hline 15.43 & 31264.7 \\
\hline 15.02 & 28124.8 \\
\hline 14.40 & 25478.0 \\
\hline 13.87 & 23623.7 \\
\hline 13.06 & 21604.0 \\
\hline 12.48 & 18678.9 \\
\hline 11.69 & 17106.4 \\
\hline 11.04 & 16371.9 \\
\hline 17.41 & 64517.6 \\
\hline 17.32 & 61863.5 \\
\hline 17.12 & 56781.2 \\
\hline 16.95 & 53041.5 \\
\hline 16.76 & 48928.1 \\
\hline 16.53 & 44841.3 \\
\hline 16.13 & 38162.6 \\
\hline 15.74 & 32984.7 \\
\hline 15.52 & 31178.9 \\
\hline 15.00 & 27672.6 \\
\hline 14.42 & 25976.2 \\
\hline 13.68 & 23317.2 \\
\hline 12.90 & 21472.4 \\
\hline 12.30 & 19314.3 \\
\hline 11.67 & 18122.7 \\
\hline 10.72 & 16335.0 \\
\hline 17.22 & 64996.6 \\
\hline 17.05 & 60878.2 \\
\hline 16.89 & 55928.6 \\
\hline 16.78 & 52846.7 \\
\hline 16.64 & 50047.8 \\
\hline 16.39 & 45036.8 \\
\hline 16.00 & 38143.9 \\
\hline 15.69 & 33788.0 \\
\hline 15.39 & 30959.9 \\
\hline 14.94 & 27888.8 \\
\hline 14.28 & 25700.9 \\
\hline 13.84 & 23574.9 \\
\hline 12.98 & 21268.0 \\
\hline 12.27 & 18893.0 \\
\hline 11.41 & 17142.5 \\
\hline 10.71 & 16247.3 \\
\hline 17.18 & 66620.4 \\
\hline 17.03 & 63457.5 \\
\hline 16.88 & 58939.9 \\
\hline 16.70 & 55018.3 \\
\hline 16.50 & 51612.1 \\
\hline 16.22 & 44861.1 \\
\hline 16.05 & 41313.2 \\
\hline & \\
\hline 13
\end{tabular}

\begin{tabular}{|l|l|}
\hline 15.71 & 36456.3 \\
\hline 15.56 & 31728.8 \\
\hline 15.16 & 28466.4 \\
\hline 14.67 & 25443.1 \\
\hline 14.08 & 24533.2 \\
\hline 13.31 & 21221.9 \\
\hline 12.79 & 19039.8 \\
\hline 18.43 & 84802.5 \\
\hline 18.11 & 82192.9 \\
\hline 17.94 & 79721.8 \\
\hline 17.72 & 75552.6 \\
\hline 17.53 & 69660.9 \\
\hline 17.37 & 65943.8 \\
\hline 17.16 & 61173.9 \\
\hline 16.94 & 56753.6 \\
\hline 16.73 & 53066.8 \\
\hline 16.43 & 46066.2 \\
\hline 16.31 & 42924.9 \\
\hline 16.04 & 38178.5 \\
\hline 15.66 & 33027.6 \\
\hline 15.36 & 30603.3 \\
\hline 14.77 & 26860.2 \\
\hline 14.20 & 24435.6 \\
\hline 13.34 & 21353.5 \\
\hline 12.89 & 19534.6 \\
\hline 12.44 & 17915.7 \\
\hline 11.90 & 17695.6 \\
\hline &
\end{tabular}

R123/PARA (98/2)

File: PARA2.dat

\begin{tabular}{|l|c|}
\hline$\Delta T_{\mathrm{s}}(\mathrm{K})$ & $q^{\prime \prime}\left(\mathrm{W} / \mathrm{m}^{2}\right)$ \\
\hline 19.03 & 83387.4 \\
\hline 18.77 & 79517.8 \\
\hline 18.51 & 78362.9 \\
\hline 18.29 & 74699.3 \\
\hline 18.10 & 70731.8 \\
\hline 17.89 & 66273.3 \\
\hline 17.77 & 63057.3 \\
\hline 17.61 & 56225.6 \\
\hline 17.33 & 50990.2 \\
\hline 17.23 & 44741.7 \\
\hline 16.98 & 40372.8 \\
\hline 16.82 & 36872.2 \\
\hline 16.43 & 31815.0 \\
\hline 15.97 & 28419.7 \\
\hline 15.49 & 25853.3 \\
\hline 14.72 & 23156.1 \\
\hline 14.13 & 20519.0 \\
\hline 13.31 & 18755.6 \\
\hline 12.88 & 18562.9 \\
\hline 19.78 & 95822.0 \\
\hline 19.52 & 92292.0 \\
\hline
\end{tabular}




\begin{tabular}{|c|c|}
\hline 19.19 & 87838.2 \\
\hline 18.93 & 84015.5 \\
\hline 18.26 & 74593.4 \\
\hline 18.02 & 71477.4 \\
\hline 17.87 & 69277.5 \\
\hline 17.59 & 62637.3 \\
\hline 17.56 & 56851.1 \\
\hline 17.48 & 52302.9 \\
\hline 17.45 & 48898.7 \\
\hline 17.24 & 41903.4 \\
\hline 17.01 & 37837.1 \\
\hline 16.60 & 33814.1 \\
\hline 16.18 & 30798.7 \\
\hline 15.63 & 26934.0 \\
\hline 15.05 & 24590.6 \\
\hline 14.42 & 23108.4 \\
\hline 13.56 & 19595.5 \\
\hline 12.91 & 18480.1 \\
\hline 12.05 & 16921.1 \\
\hline 11.25 & 15891.5 \\
\hline 10.61 & 14821.6 \\
\hline 9.81 & 13390.9 \\
\hline 8.81 & 13599.6 \\
\hline 7.90 & 11941.8 \\
\hline 7.15 & 10606.2 \\
\hline 6.16 & 9127.1 \\
\hline 5.27 & 8011.9 \\
\hline 19.42 & 88436.1 \\
\hline 19.02 & 84910.8 \\
\hline 18.76 & 81030.3 \\
\hline 18.51 & 77337.9 \\
\hline 18.26 & 72599.3 \\
\hline 18.15 & 70010.0 \\
\hline 17.96 & 65204.6 \\
\hline 17.83 & 61350.6 \\
\hline 17.60 & 54246.4 \\
\hline 17.45 & 50539.8 \\
\hline 17.31 & 46453.7 \\
\hline 16.97 & 39327.8 \\
\hline 16.81 & 35554.5 \\
\hline 16.44 & 32084.5 \\
\hline 15.96 & 28182.7 \\
\hline 15.49 & 25665.9 \\
\hline 14.76 & 23358.0 \\
\hline 13.91 & 20772.3 \\
\hline 13.35 & 19171.3 \\
\hline 12.53 & 17979.8 \\
\hline 11.80 & 16548.0 \\
\hline 10.94 & 15306.8 \\
\hline 10.23 & 14232.3 \\
\hline 9.30 & 14241.0 \\
\hline 8.28 & 12582.3 \\
\hline & \\
\hline
\end{tabular}

\begin{tabular}{|c|c|}
\hline 7.47 & 11296.8 \\
\hline 6.32 & 9213.9 \\
\hline 19.24 & 85892.6 \\
\hline 19.10 & 84642.4 \\
\hline 18.64 & 79518.1 \\
\hline 18.47 & 77001.8 \\
\hline 18.19 & 72456.9 \\
\hline 18.02 & 69026.1 \\
\hline 17.88 & 65529.0 \\
\hline 17.72 & 59168.1 \\
\hline 17.63 & 55344.3 \\
\hline 17.40 & 49898.0 \\
\hline 17.26 & 46552.3 \\
\hline 16.88 & 39142.2 \\
\hline 16.63 & 35488.3 \\
\hline 16.38 & 32455.1 \\
\hline 15.90 & 28873.8 \\
\hline 15.41 & 25719.0 \\
\hline 14.74 & 23656.2 \\
\hline 14.13 & 22044.5 \\
\hline 13.25 & 19225.7 \\
\hline 12.82 & 18730.2 \\
\hline 11.88 & 16996.5 \\
\hline 11.14 & 15829.8 \\
\hline 10.26 & 14265.3 \\
\hline 9.52 & 14849.8 \\
\hline 8.61 & 13192.6 \\
\hline 7.52 & 11152.0 \\
\hline 6.71 & 9958.1 \\
\hline 5.71 & 8222.8 \\
\hline 4.83 & 6959.6 \\
\hline 19.81 & 93462.0 \\
\hline 19.53 & 89920.9 \\
\hline 19.22 & 85222.4 \\
\hline 18.89 & 80249.8 \\
\hline 18.52 & 76806.3 \\
\hline 18.33 & 73813.5 \\
\hline 18.09 & 68867.9 \\
\hline 17.93 & 63321.6 \\
\hline 17.67 & 56584.9 \\
\hline 17.45 & 50035.4 \\
\hline 17.23 & 46732.0 \\
\hline 17.11 & 41355.3 \\
\hline 16.91 & 36750.4 \\
\hline 16.49 & 32462.1 \\
\hline 16.08 & 29618.5 \\
\hline 15.44 & 25913.0 \\
\hline 14.73 & 23778.7 \\
\hline 13.77 & 20145.0 \\
\hline 13.35 & 19221.5 \\
\hline 12.70 & 18377.0 \\
\hline 11.96 & 16964.0 \\
\hline & \\
\hline
\end{tabular}

\begin{tabular}{|c|c|}
\hline 11.10 & 15608.3 \\
\hline 10.38 & 14639.0 \\
\hline 9.51 & 14787.0 \\
\hline 8.77 & 13531.7 \\
\hline 7.33 & 10996.5 \\
\hline 6.42 & 9841.2 \\
\hline 5.58 & 8364.7 \\
\hline 4.98 & 7316.8 \\
\hline 18.01 & 60573.2 \\
\hline 17.77 & 55233.9 \\
\hline 17.35 & 42191.6 \\
\hline 16.84 & 35597.2 \\
\hline 16.03 & 29410.9 \\
\hline 14.80 & 23427.8 \\
\hline 13.31 & 18698.2 \\
\hline 11.67 & 15529.4 \\
\hline 9.65 & 14070.5 \\
\hline 19.10 & 88600.6 \\
\hline 18.54 & 78050.7 \\
\hline 18.12 & 69518.7 \\
\hline 17.99 & 61993.4 \\
\hline 17.72 & 54150.4 \\
\hline 17.48 & 48425.1 \\
\hline 17.17 & 40315.8 \\
\hline 16.56 & 32595.3 \\
\hline 15.64 & 26737.2 \\
\hline 14.67 & 23216.7 \\
\hline 13.04 & 18663.5 \\
\hline 11.66 & 16062.9 \\
\hline 10.15 & 13633.6 \\
\hline 8.71 & 12798.0 \\
\hline 6.39 & 9744.0 \\
\hline 4.38 & 6160.1 \\
\hline & \\
\hline
\end{tabular}

R123/PARA/PG

File: PARAPG.dat

\begin{tabular}{|c|c|}
\hline$\Delta T_{\mathrm{s}}(\mathrm{K})$ & $q^{\prime \prime}\left(\mathrm{W} / \mathrm{m}^{2}\right)$ \\
\hline 18.52 & 75389.6 \\
\hline 18.23 & 67941.5 \\
\hline 17.99 & 61941.4 \\
\hline 17.86 & 56776.8 \\
\hline 17.56 & 48877.0 \\
\hline 17.34 & 42323.0 \\
\hline 16.82 & 34914.2 \\
\hline 16.10 & 29003.0 \\
\hline 14.79 & 23543.3 \\
\hline 13.77 & 20023.4 \\
\hline 12.76 & 17490.1 \\
\hline 11.83 & 16423.1 \\
\hline 10.71 & 14579.4 \\
\hline 9.36 & 13928.2 \\
\hline 7.80 & 11373.6 \\
\hline
\end{tabular}




\begin{tabular}{|c|c|}
\hline 19.02 & 84018.0 \\
\hline 18.65 & 75652.9 \\
\hline 18.15 & 66693.6 \\
\hline 17.92 & 58932.5 \\
\hline 17.61 & 51510.6 \\
\hline 17.41 & 46376.2 \\
\hline 16.87 & 35430.5 \\
\hline 16.03 & 28370.9 \\
\hline 15.03 & 24682.7 \\
\hline 14.18 & 20935.8 \\
\hline 12.82 & 17658.9 \\
\hline 11.74 & 16640.8 \\
\hline 10.40 & 14333.0 \\
\hline 9.33 & 14362.0 \\
\hline 7.93 & 11714.6 \\
\hline 6.77 & 10059.1 \\
\hline 5.32 & 7513.8 \\
\hline 19.16 & 87538.1 \\
\hline 18.76 & 78591.6 \\
\hline 18.40 & 73569.1 \\
\hline 18.18 & 69209.6 \\
\hline 17.90 & 60218.3 \\
\hline 17.45 & 50465.8 \\
\hline 17.11 & 42807.8 \\
\hline 16.71 & 35346.1 \\
\hline 16.17 & 30489.8 \\
\hline 15.34 & 25240.7 \\
\hline 14.43 & 22394.0 \\
\hline 13.72 & 20650.6 \\
\hline 12.75 & 17390.0 \\
\hline 11.41 & 15767.1 \\
\hline 10.20 & 13738.0 \\
\hline 8.92 & 13443.6 \\
\hline 7.58 & 11163.3 \\
\hline 6.30 & 9265.5 \\
\hline 5.14 & 7398.3 \\
\hline 4.05 & 5600.9 \\
\hline & \\
\hline
\end{tabular}

\section{R123/PARA/LP1}

File: PARALP1.dat

\begin{tabular}{|c|c|}
\hline$\Delta T_{\mathrm{s}}(\mathrm{K})$ & $q^{\prime \prime}\left(\mathrm{W} / \mathrm{m}^{2}\right)$ \\
\hline 18.93 & 89371.8 \\
\hline 18.59 & 84675.3 \\
\hline 18.45 & 81828.4 \\
\hline 18.15 & 75327.7 \\
\hline 18.12 & 74006.9 \\
\hline 17.98 & 69674.6 \\
\hline 17.92 & 66965.8 \\
\hline 17.81 & 60515.6 \\
\hline 17.74 & 56478.3 \\
\hline 17.66 & 52470.4 \\
\hline 17.44 & 47686.9 \\
\hline
\end{tabular}

\begin{tabular}{|c|c|}
\hline 17.06 & 40883.3 \\
\hline 16.80 & 37061.0 \\
\hline 16.35 & 32252.7 \\
\hline 15.85 & 28673.4 \\
\hline 15.34 & 26367.2 \\
\hline 14.78 & 24009.5 \\
\hline 14.25 & 21373.1 \\
\hline 13.53 & 19633.5 \\
\hline 12.74 & 17577.6 \\
\hline 12.10 & 17057.8 \\
\hline 11.23 & 15305.1 \\
\hline 10.63 & 13994.6 \\
\hline 9.69 & 14196.0 \\
\hline 8.70 & 12823.5 \\
\hline 7.85 & 11436.2 \\
\hline 6.61 & 9505.7 \\
\hline 5.99 & 8574.8 \\
\hline 5.01 & 6623.5 \\
\hline 19.23 & 91803.1 \\
\hline 19.04 & 88783.1 \\
\hline 18.90 & 86129.4 \\
\hline 18.58 & 78884.7 \\
\hline 18.52 & 78047.5 \\
\hline 18.36 & 72119.5 \\
\hline 18.21 & 68119.0 \\
\hline 18.07 & 63441.8 \\
\hline 17.95 & 58799.6 \\
\hline 17.74 & 52206.4 \\
\hline 17.67 & 49223.3 \\
\hline 17.59 & 46295.3 \\
\hline 17.35 & 41618.4 \\
\hline 17.01 & 37346.6 \\
\hline 16.54 & 32411.0 \\
\hline 16.12 & 29224.1 \\
\hline 15.48 & 25891.6 \\
\hline 14.90 & 23755.9 \\
\hline 13.97 & 20633.4 \\
\hline 13.43 & 19148.5 \\
\hline 12.64 & 17142.7 \\
\hline 12.00 & 16381.3 \\
\hline 11.149 & 14920.9 \\
\hline 10.52 & 13956.0 \\
\hline 9.63 & 13938.6 \\
\hline 8.63 & 12325.7 \\
\hline 7.84 & 11077.7 \\
\hline 6.83 & 9357.8 \\
\hline 5.73 & 7869.8 \\
\hline 19.08 & 87687.1 \\
\hline 18.95 & 85005.1 \\
\hline 18.72 & 80083.1 \\
\hline 18.54 & 73853.9 \\
\hline 18.45 & 71163.1 \\
\hline & \\
\hline
\end{tabular}

\begin{tabular}{|c|c|}
\hline 18.31 & 67215.6 \\
\hline 18.27 & 64663.6 \\
\hline 18.06 & 56897.8 \\
\hline 17.99 & 55930.6 \\
\hline 17.76 & 49788.2 \\
\hline 17.53 & 45156.3 \\
\hline 17.30 & 40516.9 \\
\hline 17.09 & 37004.0 \\
\hline 16.76 & 34149.3 \\
\hline 16.19 & 29284.3 \\
\hline 15.51 & 25451.6 \\
\hline 14.84 & 21753.2 \\
\hline 14.38 & 20863.4 \\
\hline 13.70 & 19321.7 \\
\hline 12.88 & 17273.9 \\
\hline 12.13 & 15616.9 \\
\hline 11.46 & 15193.7 \\
\hline 10.63 & 13767.7 \\
\hline 9.84 & 14429.7 \\
\hline 9.08 & 12974.0 \\
\hline 8.02 & 11342.2 \\
\hline 7.16 & 10146.2 \\
\hline 6.18 & 8621.0 \\
\hline 5.34 & 7167.0 \\
\hline 19.25 & 91824.0 \\
\hline 19.06 & 87816.6 \\
\hline 18.96 & 83937.5 \\
\hline 18.75 & 80362.6 \\
\hline 18.59 & 76691.3 \\
\hline 18.44 & 70509.9 \\
\hline 18.33 & 67611.1 \\
\hline 18.20 & 63075.5 \\
\hline 18.07 & 58622.3 \\
\hline 17.91 & 54519.7 \\
\hline 17.69 & 49531.2 \\
\hline 17.54 & 46166.8 \\
\hline 17.16 & 39532.2 \\
\hline 16.97 & 37176.3 \\
\hline 16.523 & 32528.1 \\
\hline 16.15 & 29667.3 \\
\hline 15.46 & 25655.2 \\
\hline 14.78 & 23302.4 \\
\hline 14.11 & 20965.2 \\
\hline 13.56 & 19763.9 \\
\hline 12.78 & 17707.7 \\
\hline 12.10 & 16904.5 \\
\hline 11.35 & 15062.3 \\
\hline 10.51 & 13720.9 \\
\hline 9.74 & 14207.6 \\
\hline 8.91 & 12817.9 \\
\hline 7.64 & 11120.5 \\
\hline 7.02 & 9972.6 \\
\hline & \\
\hline
\end{tabular}




\begin{tabular}{|l|l|}
\hline 6.02 & 8178.3 \\
\hline 4.85 & 6413.4 \\
\hline
\end{tabular}


Table 4 Number of test days and data points

\begin{tabular}{|c|c|c|}
\hline Fluid (\% mass fraction) & Number of days & Number of data points \\
\hline $\begin{array}{c}\text { Pure R123 } \\
7.5 \mathrm{~K} \leq \Delta T_{\mathrm{s}} \leq 16.5 \mathrm{~K}\end{array}$ & 6 & 100 \\
\hline $\begin{array}{c}\text { R123/PARA }(99.5 / 0.5) \\
9 \mathrm{~K} \leq \Delta T_{\mathrm{s}} \leq 18 \mathrm{~K}\end{array}$ & 5 & 88 \\
\hline $\mathrm{R} 123 / \mathrm{PARA}(99 / 1)$ & 5 & 84 \\
$10.5 \mathrm{~K} \leq \Delta T_{\mathrm{s}} \leq 18 \mathrm{~K}$ & & 158 \\
\hline $\begin{array}{c}\text { R123/PARA }(98 / 2) \\
5 \mathrm{~K} \leq \Delta T_{\mathrm{s}} \leq 20 \mathrm{~K}\end{array}$ & 7 & 52 \\
\hline $\begin{array}{c}\text { R123/PARA/PG }(97.8 / 2 / 0.2) \\
5 \mathrm{~K} \leq \Delta T_{\mathrm{s}} \leq 19 \mathrm{~K}\end{array}$ & 3 & 117 \\
\hline $\begin{array}{c}\mathrm{R} 123 / \mathrm{PARA} / \mathrm{LP} 1(97.8 / 2 / 0.2) \\
5 \mathrm{~K} \leq \Delta T_{\mathrm{s}} \leq 19.5 \mathrm{~K}\end{array}$ & 4 & \\
\hline
\end{tabular}

Table 5 Estimated parameters for cubic boiling curve fits for plain copper surface $\Delta T_{\mathrm{s}}=\mathrm{A}_{0}+\mathrm{A}_{1} q " \mathrm{~A}_{2} q^{\prime \prime 2}+\mathrm{A}_{3} q^{\prime 3}$

$\Delta T_{\mathrm{s}}$ in Kelvin and $q$ " in $\mathrm{W} / \mathrm{m}^{2}$

\begin{tabular}{|c|c|c|c|c|}
\hline Fluid & $\mathrm{A}_{\mathrm{o}}$ & $\mathrm{A}_{1}$ & $\mathrm{~A}_{2}$ & $\mathrm{~A}_{3}$ \\
\hline PureR123 & & & & \\
\hline $6 \mathrm{~K} \leq \Delta T_{\mathrm{s}} \leq 14.5 \mathrm{~K}$ & -13.5834 & $2.48902 \times 10^{-3}$ & $-7.70987 \times 10^{-8}$ & $8.18448 \times 10^{-13}$ \\
\hline $14.5 \mathrm{~K} \leq \Delta T_{\mathrm{s}} \leq 16.5 \mathrm{~K}$ & 11.9188 & $9.93197 \times 10^{-5}$ & $-1.13967 \times 10^{-9}$ & $5.77704 \times 10^{-15}$ \\
\hline R123/PARA (99.5/0.5) & & & & \\
\hline $9 \mathrm{~K} \leq \Delta T_{\mathrm{s}} \leq 15.5 \mathrm{~K}$ & -6.90657 & $1.60725 \times 10^{-3}$ & $-3.93167 \times 10^{-8}$ & $3.27067 \times 10^{-13}$ \\
\hline $14.5 \mathrm{~K} \leq \Delta T_{\mathrm{s}} \leq 18 \mathrm{~K}$ & 11.7559 & $1.44116 \times 10^{-4}$ & $-1.63992 \times 10^{-9}$ & $8.78834 \times 10^{-15}$ \\
\hline R123/PARA (99/1) & & & & \\
\hline $10.5 \mathrm{~K} \leq \Delta T_{\mathrm{s}} \leq 16 \mathrm{~K}$ & -1.62317 & $1.11913 \times 10^{-3}$ & $-2.31487 \times 10^{-8}$ & $1.54542 \times 10^{-13}$ \\
\hline $15.5 \mathrm{~K} \leq \Delta T_{\mathrm{s}} \leq 18 \mathrm{~K}$ & 11.9169 & $1.68801 \times 10^{-4}$ & $-2.05499 \times 10^{-9}$ & $1.11276 \times 10^{-14}$ \\
\hline R123/PARA (98/2) & & & & \\
\hline $5 \mathrm{~K} \leq \Delta T_{\mathrm{s}} \leq 16.5 \mathrm{~K}$ & -2.68251 & $1.04636 \times 10^{-3}$ & $-8.12573 \times 10^{-9}$ & $-1.92917 \times 10^{-13}$ \\
\hline $15 \mathrm{~K} \leq \Delta T_{\mathrm{s}} \leq 20 \mathrm{~K}$ & 8.98216 & $3.90307 \times 10^{-4}$ & $-6.10689 \times 10^{-9}$ & $3.41756 \times 10^{-14}$ \\
\hline R123/PARA/PG (97.8/2/0.2) & & & & \\
\hline $5 \mathrm{~K} \leq \Delta T_{\mathrm{s}} \leq 16 \mathrm{~K}$ & 3.79045 & $-3.55922 \times 10^{-4}$ & $8.78467 \times 10^{-8}$ & $-2.24414 \times 10^{-12}$ \\
\hline $15 \mathrm{~K} \leq \Delta T_{\mathrm{s}} \leq 19 \mathrm{~K}$ & 8.90035 & $3.95287 \times 10^{-4}$ & $-6.14104 \times 10^{-9}$ & $3.43387 \times 10^{-14}$ \\
\hline $\begin{array}{l}\text { R123/PARA/LP1 (97.8/2/0.2) } \\
\end{array}$ & & & & \\
\hline $5 \mathrm{~K} \leq \Delta T_{\mathrm{s}} \leq 17 \mathrm{~K}$ & -3.67750 & $1.34398 \times 10^{-3}$ & $-2.67061 \times 10^{-8}$ & $1.38544 \times 10^{-13}$ \\
\hline $15 \mathrm{~K} \leq \Delta T_{\mathrm{s}} \leq 19.5 \mathrm{~K}$ & 8.87760 & $3.85489 \times 10^{-4}$ & $-5.62173 \times 10^{-9}$ & $2.89907 \times 10^{-14}$ \\
\hline
\end{tabular}


Table 6 Residual standard deviation of $\Delta T_{\mathrm{s}}$

\begin{tabular}{|c|c|}
\hline Fluid & $u(\mathrm{~K})$ \\
\hline PureR123 & \\
$6 \mathrm{~K} \leq \Delta T_{\mathrm{s}} \leq 14.5 \mathrm{~K}$ & 0.27 \\
$14.5 \mathrm{~K} \leq \Delta T_{\mathrm{s}} \leq 16.5 \mathrm{~K}$ & 0.05 \\
\hline $\mathrm{R} 123 / \mathrm{PARA}(99.5 / 0.5)$ & \\
$9 \mathrm{~K} \leq \Delta T_{\mathrm{s}} \leq 15.5 \mathrm{~K}$ & 0.23 \\
$14.5 \mathrm{~K} \leq \Delta T_{\mathrm{s}} \leq 18 \mathrm{~K}$ & 0.10 \\
\hline $\mathrm{R} 123 / \mathrm{PARA}(99 / 1)$ & \\
$10.5 \mathrm{~K} \leq \Delta T_{\mathrm{s}} \leq 16 \mathrm{~K}$ & 0.21 \\
$15.5 \mathrm{~K} \leq \Delta T_{\mathrm{s}} \leq 18 \mathrm{~K}$ & 0.11 \\
\hline $\mathrm{R} 123 / \mathrm{PARA}(98 / 2)$ & \\
$5 \mathrm{~K} \leq \Delta T_{\mathrm{s}} \leq 16.5 \mathrm{~K}$ & 0.35 \\
$15 \mathrm{~K} \leq \Delta T_{\mathrm{s}} \leq 20 \mathrm{~K}$ & 0.11 \\
\hline $\mathrm{R} 123 / \mathrm{PARA} / \mathrm{PG}(97.8 / 2 / 0.2)$ & \\
$5 \mathrm{~K} \leq \Delta T_{\mathrm{s}} \leq 16 \mathrm{~K}$ & 0.33 \\
$15 \mathrm{~K} \leq \Delta T_{\mathrm{s}} \leq 19 \mathrm{~K}$ & 0.10 \\
\hline $\mathrm{R} 123 / \mathrm{PARA} / \mathrm{LP} 1(97.8 / 2 / 0.2)$ & \\
$5 \mathrm{~K} \leq \Delta T_{\mathrm{s}} \leq 17 \mathrm{~K}$ & 0.38 \\
$15 \mathrm{~K} \leq \Delta T_{\mathrm{s}} \leq 19.5 \mathrm{~K}$ & 0.13 \\
\hline
\end{tabular}


Table 7 Average magnitude of $95 \%$ multi-use confidence interval for mean $T_{\mathrm{w}}-T_{\mathrm{s}}(\mathrm{K})$

\begin{tabular}{|c|c|}
\hline Fluid & $u(\mathrm{~K})$ \\
\hline PureR 123 & \\
$6 \mathrm{~K} \leq \Delta T_{\mathrm{s}} \leq 14.5 \mathrm{~K}$ & 0.26 \\
$14.5 \mathrm{~K} \leq \Delta T_{\mathrm{s}} \leq 16.5 \mathrm{~K}$ & 0.04 \\
\hline $\mathrm{R} 123 / \mathrm{PARA}(99.5 / 0.5)$ & \\
$9 \mathrm{~K} \leq \Delta T_{\mathrm{s}} \leq 15.5 \mathrm{~K}$ & 0.24 \\
$14.5 \mathrm{~K} \leq \Delta T_{\mathrm{s}} \leq 18 \mathrm{~K}$ & 0.09 \\
\hline $\mathrm{R} 123 / \mathrm{PARA}(99 / 1)$ & \\
$10.5 \mathrm{~K} \leq \Delta T_{\mathrm{s}} \leq 16 \mathrm{~K}$ & 0.22 \\
$15.5 \mathrm{~K} \leq \Delta T_{\mathrm{s}} \leq 18 \mathrm{~K}$ & 0.10 \\
\hline $\mathrm{R} 123 / \mathrm{PARA}(98 / 2)$ & \\
$5 \mathrm{~K} \leq \Delta T_{\mathrm{s}} \leq 16.5 \mathrm{~K}$ & 0.26 \\
$15 \mathrm{~K} \leq \Delta T_{\mathrm{s}} \leq 20 \mathrm{~K}$ & 0.08 \\
\hline $\mathrm{R} 123 / \mathrm{PARA} / \mathrm{PG}(97.8 / 2 / 0.2)$ & \\
$5 \mathrm{~K} \leq \Delta T_{\mathrm{s}} \leq 16 \mathrm{~K}$ & 0.46 \\
$15 \mathrm{~K} \leq \Delta T_{\mathrm{s}} \leq 19 \mathrm{~K}$ & 0.14 \\
\hline $\mathrm{R} 123 / \mathrm{PARA} / \mathrm{LP} 1(97.8 / 2 / 0.2)$ & \\
$5 \mathrm{~K} \leq \Delta T_{\mathrm{s}} \leq 17 \mathrm{~K}$ & 0.31 \\
$15 \mathrm{~K} \leq \Delta T_{\mathrm{s}} \leq 19.5 \mathrm{~K}$ & 0.11 \\
\hline
\end{tabular}




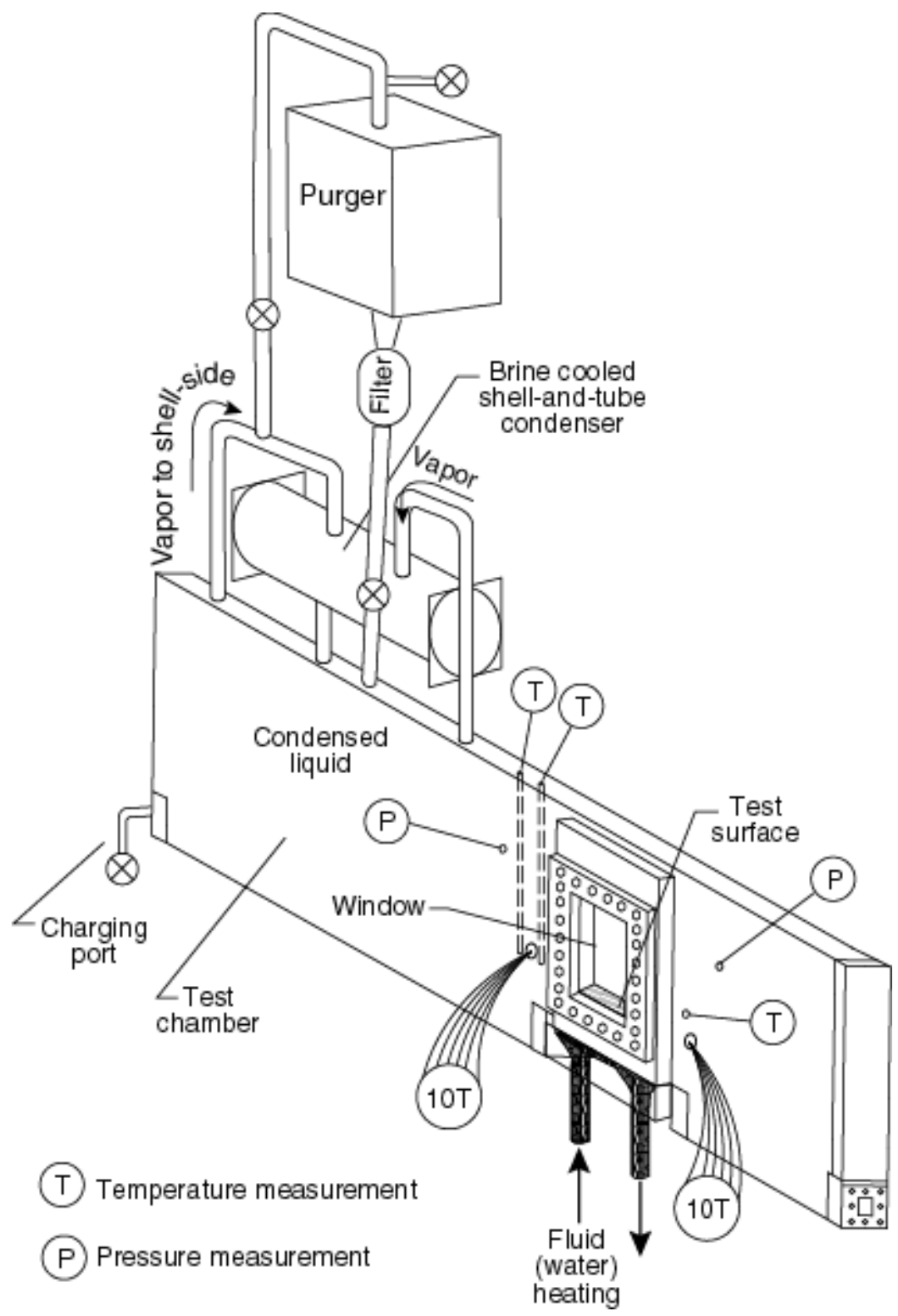

Fig. 1 Schematic of test apparatus 


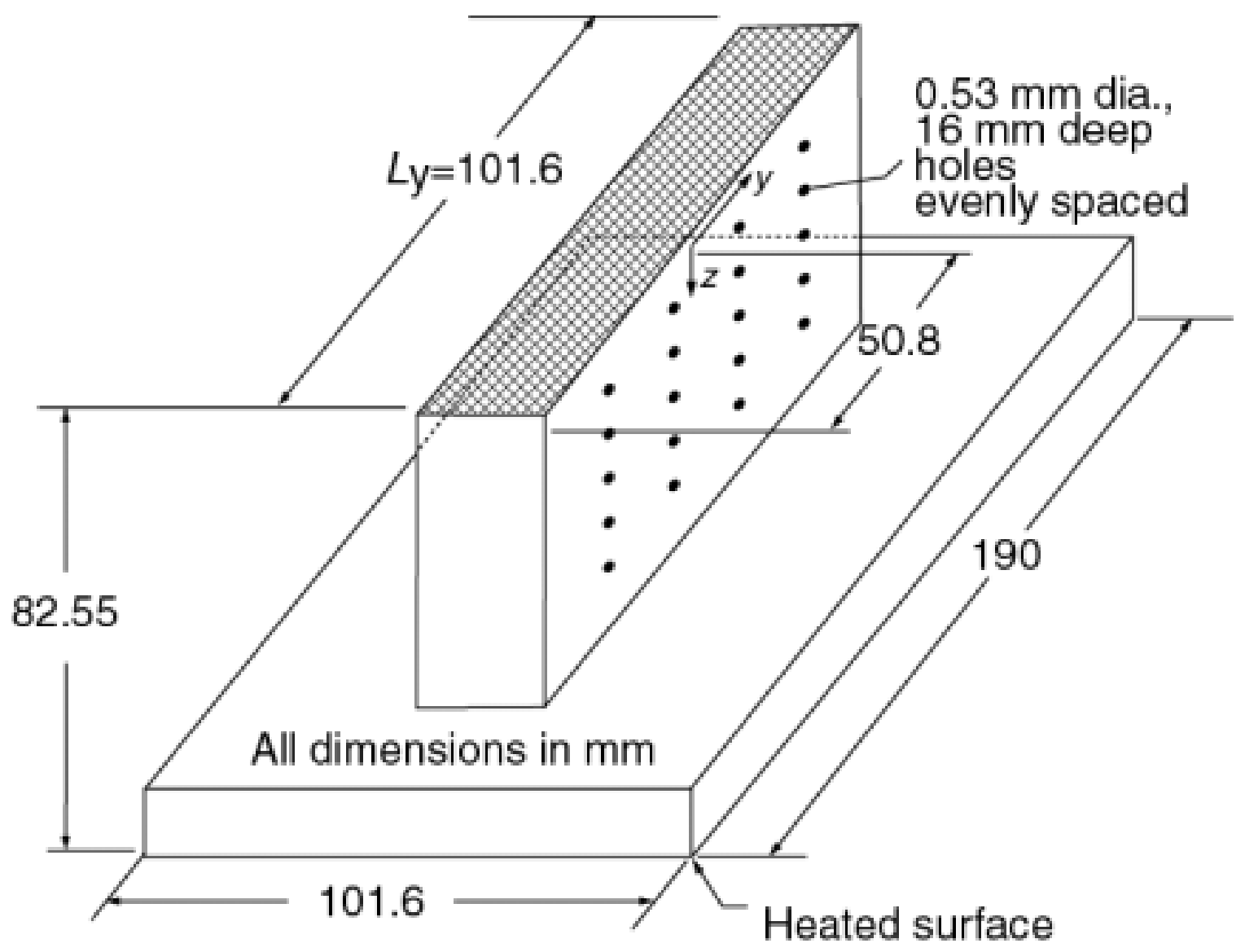

Fig. 2 OFHC copper flat test plate with cross-hatched surface and thermocouple coordinate system 


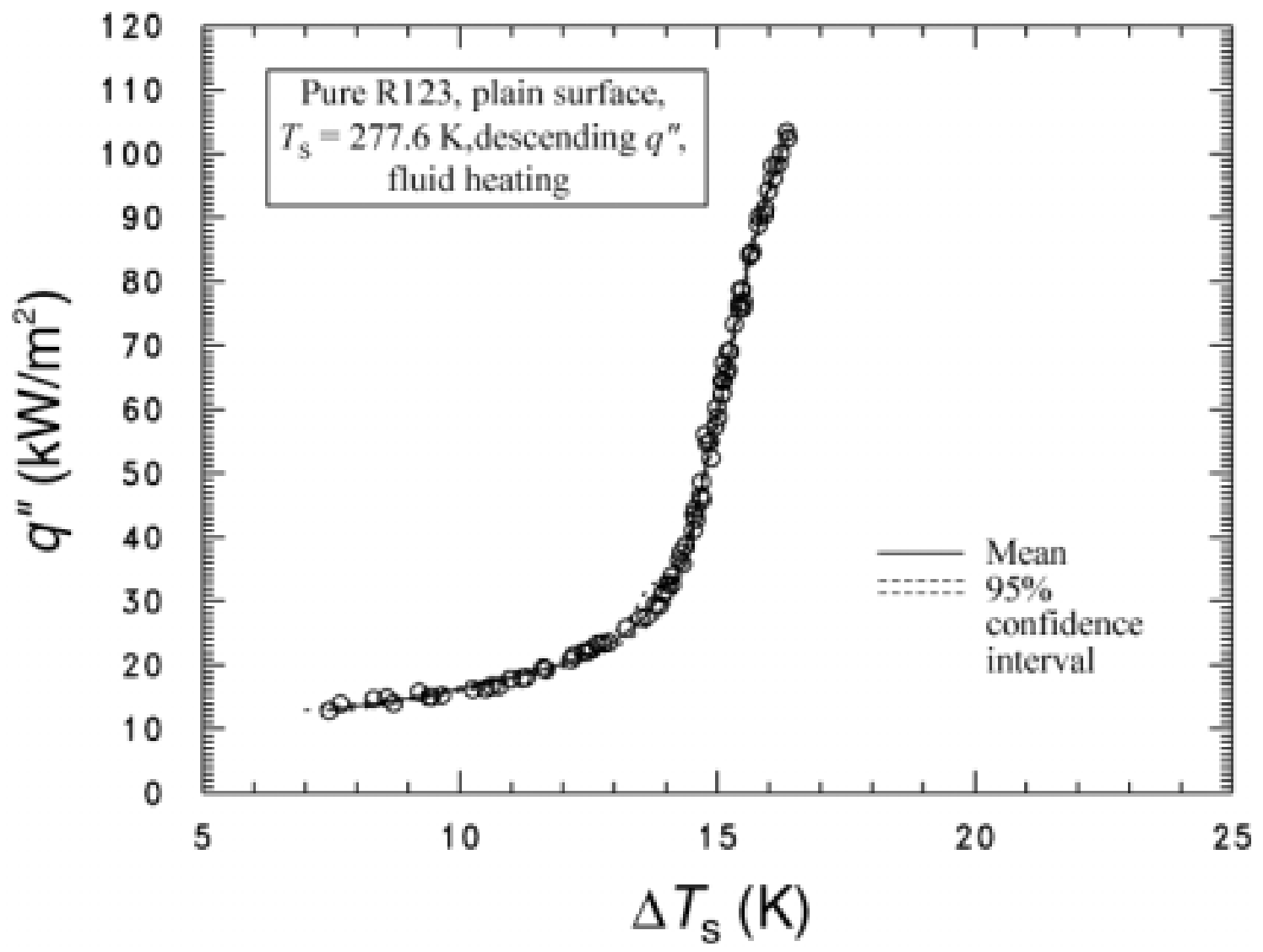

Fig. 3 Pure R123 boiling curve for plain surface 


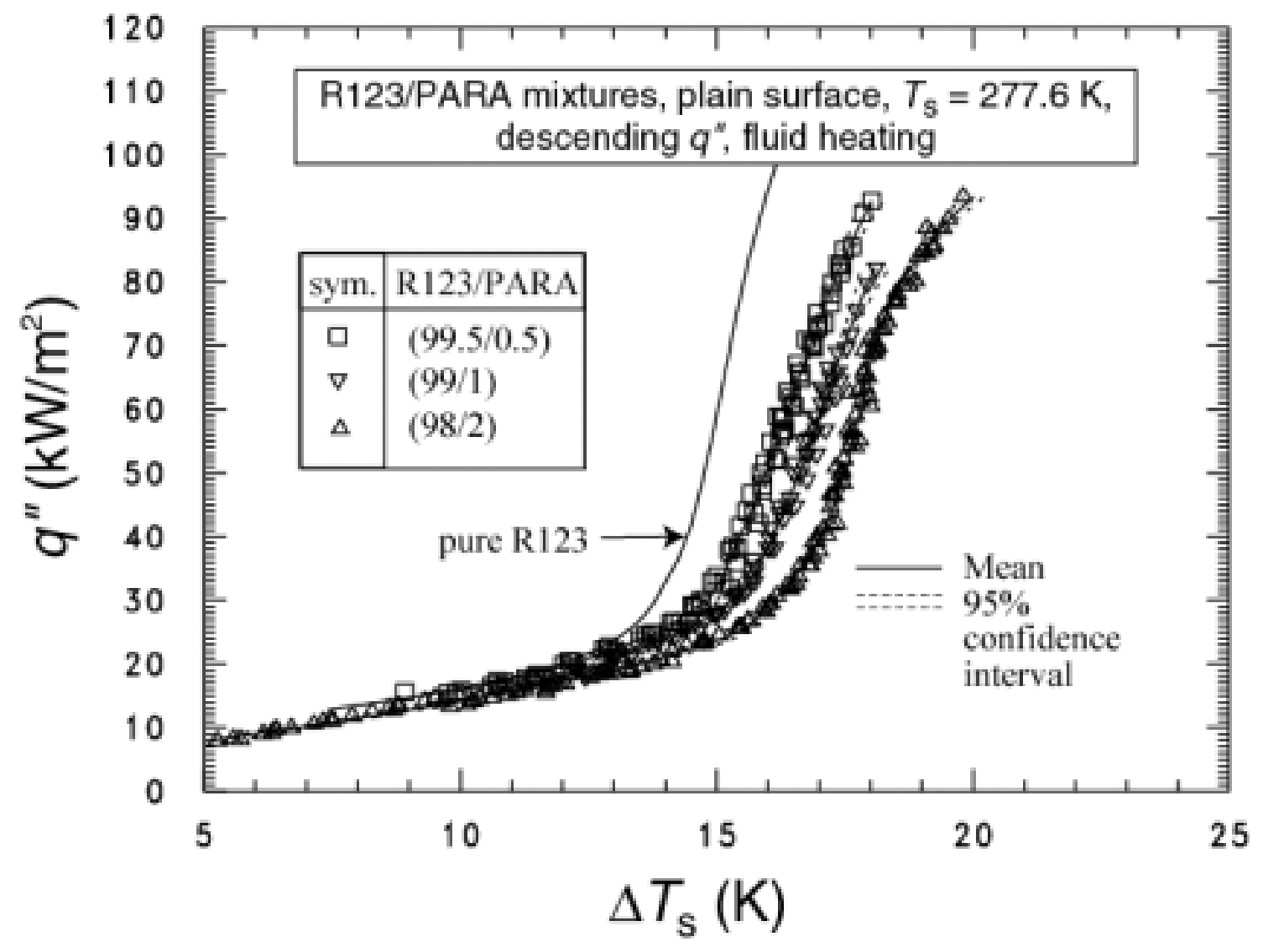

Fig. 4 R134a /PARA mixtures boiling curves for plain surface 


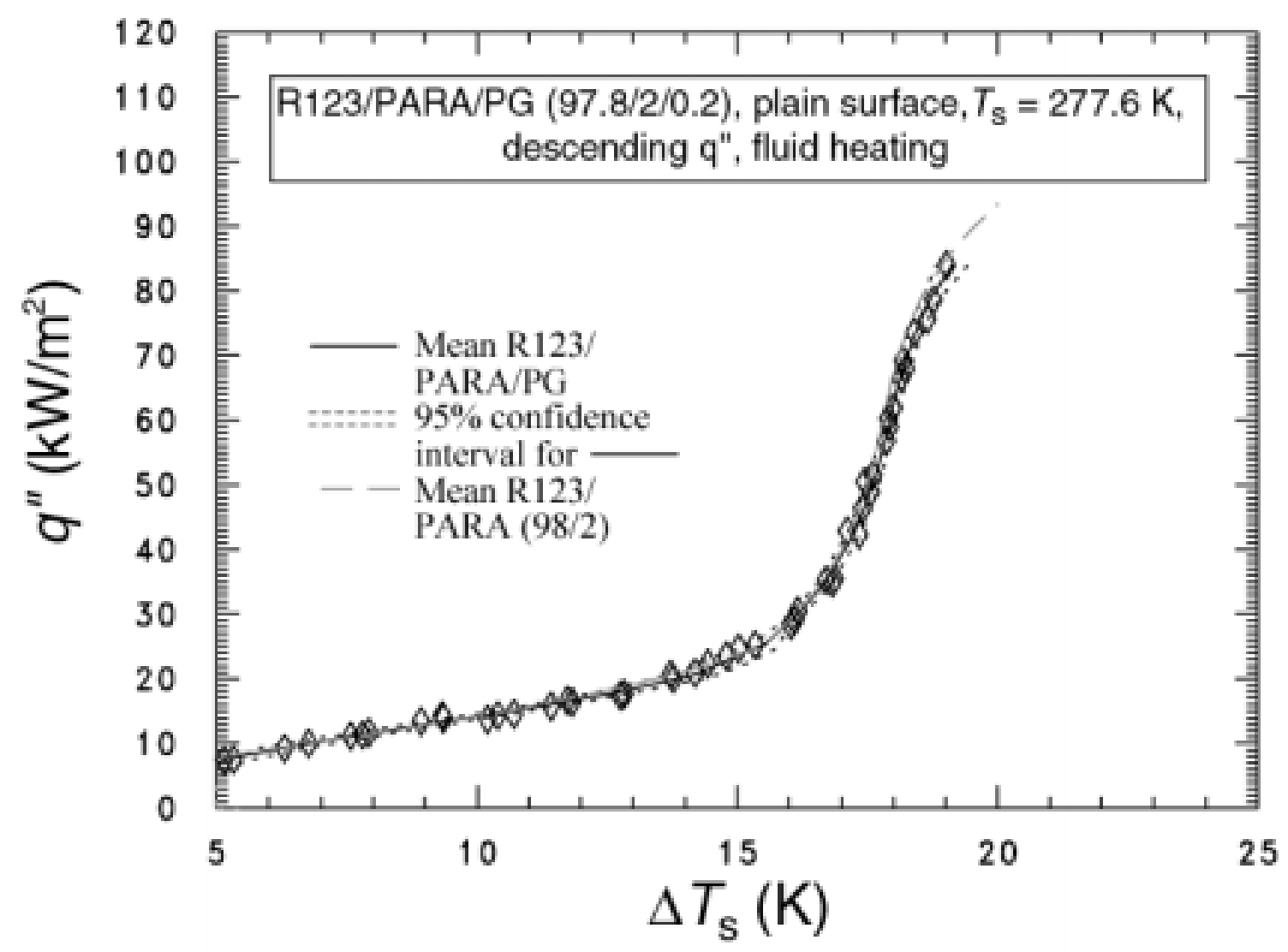

Fig. 5 R123/PARA/PG (97.8/2/0.2) boiling curve for plain surface 


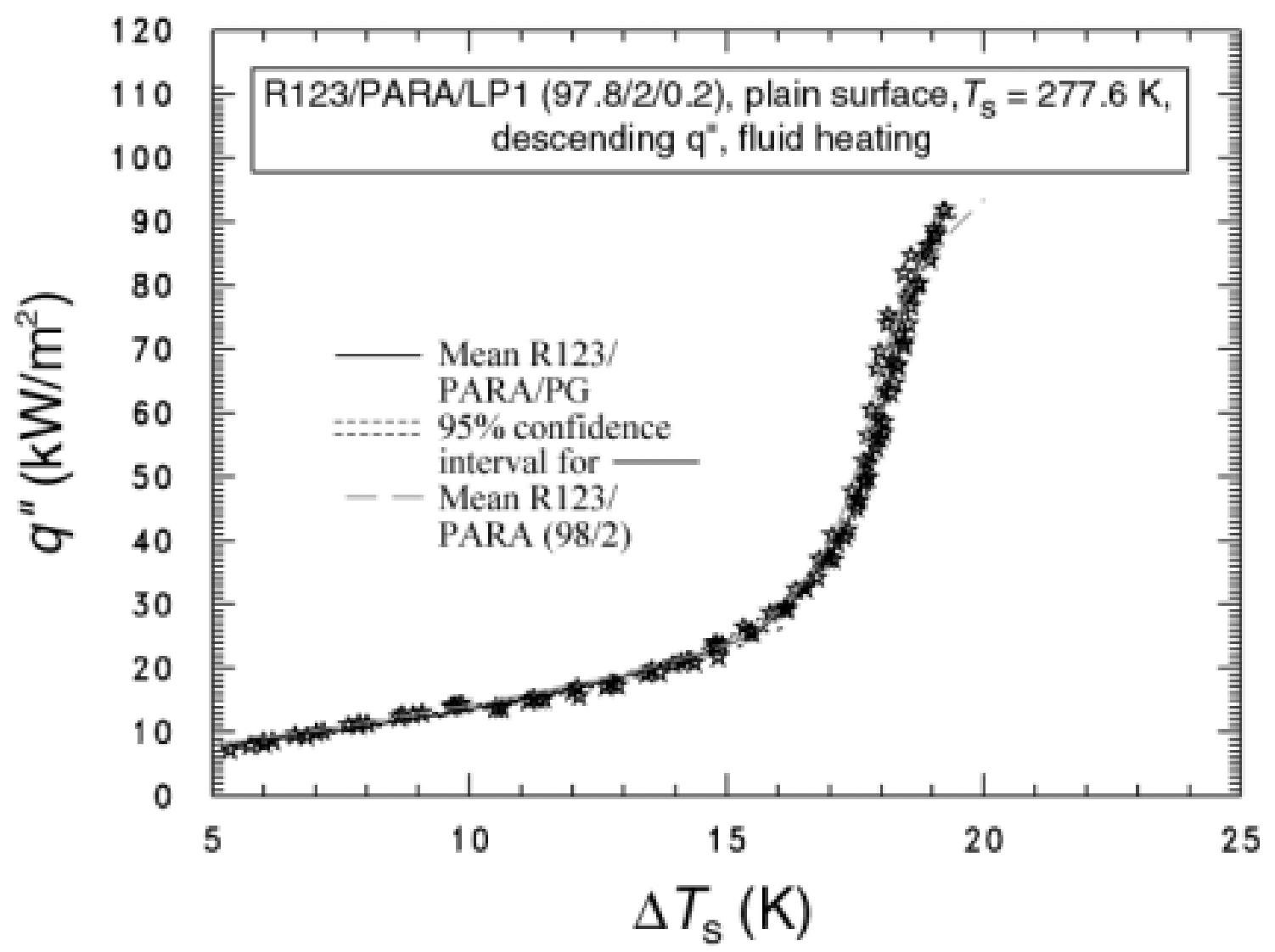

Fig. 6 R123/PARA/LP1 (97.8/2/0.2) boiling curve for plain surface 


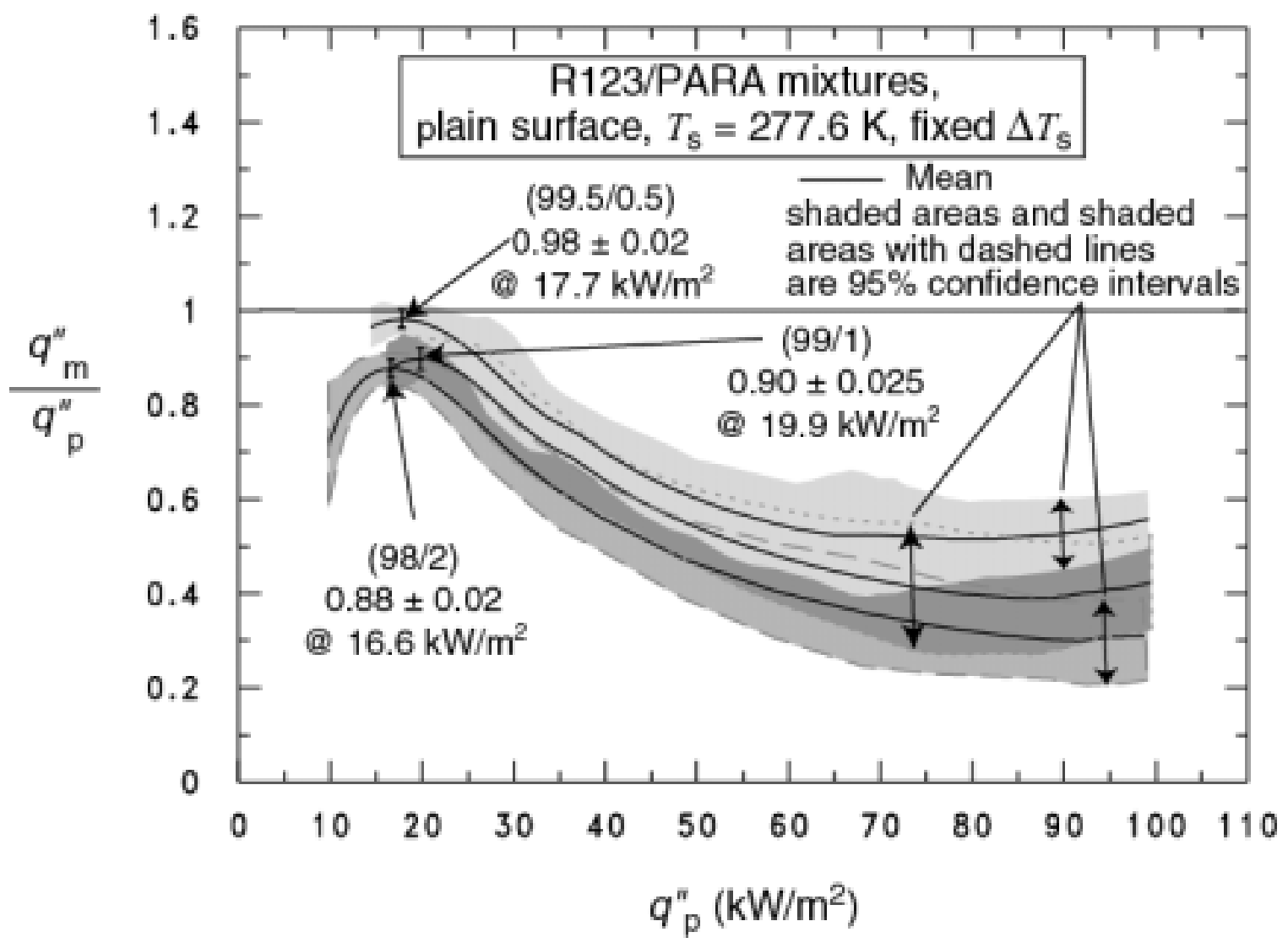

Fig. 7 R123/PARA mixture heat fluxes relative to that of pure R123 for a plain surface 


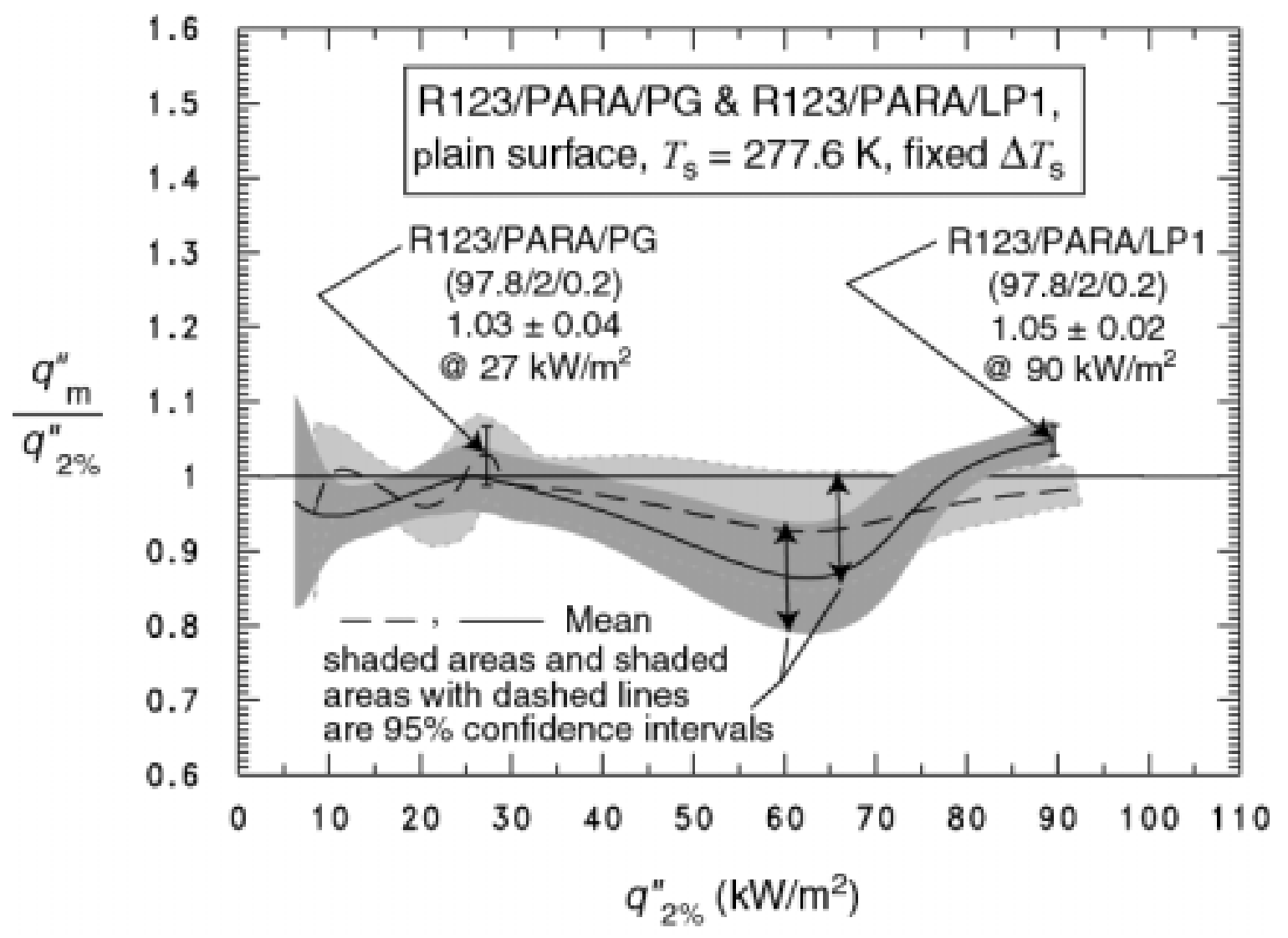

Fig. 8 R123/PARA/PG (97.8/2/0.2) and R123/PARA/LP1 (97.8/2/0.2) mixture heat fluxes relative to that of the R123/PARA (98/2) mixture for a plain surface 


\section{APPENDIX A: ADDITIVE POTENTIAL}

This appendix presents the results of a thermodynamic cycle and heat transfer analysis to determine the potential improvement in chiller coefficient of performance (COP) as caused by a given improvement in refrigerant side boiling heat transfer. The design conditions and operating specifications of a representative $1110 \mathrm{~kW}$ (315 ton), R11 chiller manufactured in the year 1985 was chosen as the baseline and taken from the manufacturer's catalog data. The entering and exiting sink and source temperatures were taken from design conditions for the chiller and held constant throughout the analysis. The entering and leaving condenser water temperature was $302.6 \mathrm{~K}$ and $307.9 \mathrm{~K}$, respectively. The entering and leaving evaporator water temperature was $285.4 \mathrm{~K}$ and $279.8 \mathrm{~K}$, respectively. The baseline Log-Mean-Temperature-Difference of the condenser $\left(\mathrm{LMTD}_{\mathrm{Bc}}\right)$ and that of the evaporator $\left(\mathrm{LMTD}_{\mathrm{Be}}\right)$ before additive treatment was $5.6 \mathrm{~K}$ and 3.4 K, respectively. Figure A.1 taken from Fischer et al. (1994), roughly confirms the representative value of the reported COP for the baseline chiller at approximately 5.65 for the year 1985. The analysis assumed isenthalphic expansion and adiabatic compression at an isentropic efficiency of 0.721 . The compressor efficiency was chosen so that the cycle would match the quoted COP of the baseline chiller and was held constant throughout the analysis.

The split of the water-side/refrigerant-side heat transfer resistance for the evaporator of the baseline chiller was found to be $68 \% / 32 \%$. In other words, the refrigerant-side temperature difference $\left(\Delta T_{\mathrm{r}}\right)$ and the water-side temperature difference $\left(\Delta T_{\mathrm{w}}\right)$ were $68 \%$ and $32 \%$ of the LMTD, respectively:

$$
\mathrm{LMTD}=\Delta T_{\mathrm{r}}+\Delta T_{\mathrm{w}}=0.32 \mathrm{LMTD}_{\mathrm{B}}+0.68 \mathrm{LMTD}_{\mathrm{B}}
$$

The percent increase in the refrigerant-side heat transfer coefficient $\left(E_{\mathrm{h}}\right)$ was used to reduce the magnitude of the refrigerant-side heat transfer resistance while maintaining the magnitude of the original baseline water-side resistance. Hence, the improved LMTD for the evaporator was calculated as:

$$
\operatorname{LMTD}_{\mathrm{e}}=\left(\frac{0.32}{1+\frac{E_{h}}{100}}+0.68\right) \operatorname{LMTD}_{\text {B }}
$$

Kedzierski (2000b) has shown that a boiling additive can degrade the condensation heat transfer by as much as $10 \%$. Based on this, it was assumed that the additive caused a $10 \%$ reduction in the refrigerant-side heat transfer coefficient in the condenser. The LMTD for the condenser was calculated as:

$$
\mathrm{LMTD}_{\mathrm{c}}=0.68 \mathrm{LMTD}_{\mathrm{Bc}}+\frac{0.32}{0.9} \mathrm{LMTD}_{\mathrm{Bc}} \approx 1.04 \mathrm{LMTD}_{\mathrm{Bc}}
$$

Figure A.2 shows the percent increase in the $\mathrm{COP}\left(E_{\mathrm{COP}}\right)$ for a given $E_{\mathrm{h}}$ and the assumptions of the analysis. Because of the heat transfer degradation in the condenser, 
performance improvements are not realized until the evaporator heat transfer enhanced by more than $25 \%$. The figure also shows that if the boiling performance of a representative 1985 chiller could be improved by $100 \%$, the chiller would realize an improvement of approximately $1 \%$ in the COP. The chiller COP would be improved by approximately $1.5 \%$ for an $E_{\mathrm{h}}$ of $225 \%$.

Figure A.2 also shows the $E_{\mathrm{h}}$ for the case where there is no condenser penalty for heat transfer degradation as caused by the additive. A $10 \%$ reduction in the refrigerant-side heat transfer coefficient in the condenser has caused approximately a $0.7 \%$ loss in COP for $E_{\mathrm{h}}$ between $25 \%$ and $275 \%$.

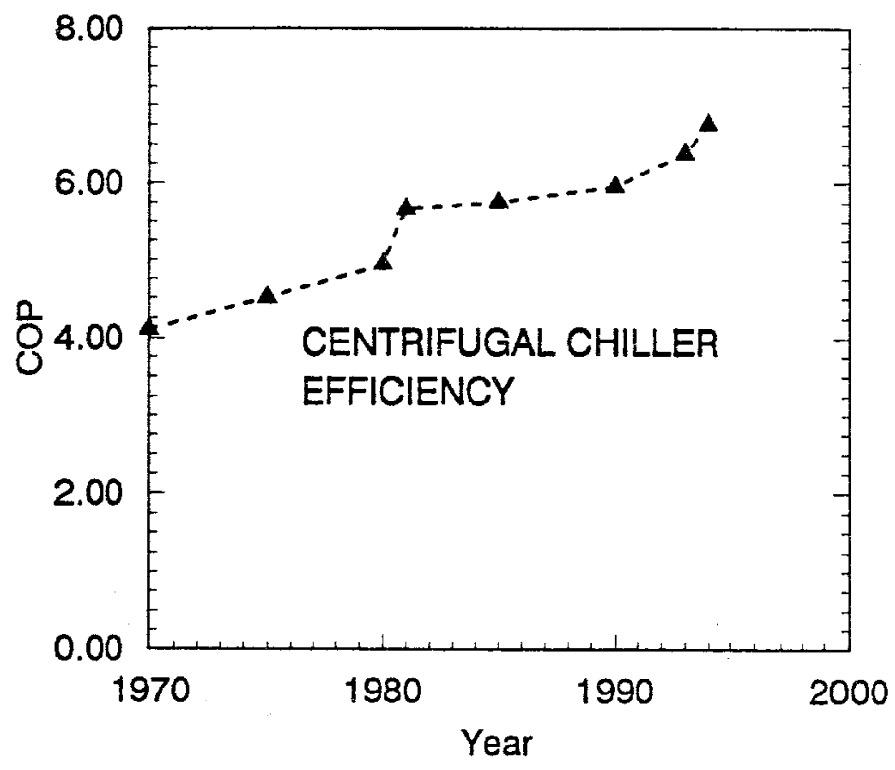

Fig. A.1 Efficiency of centrifugal chillers at industry rating conditions (Fischer et al., 1994) 


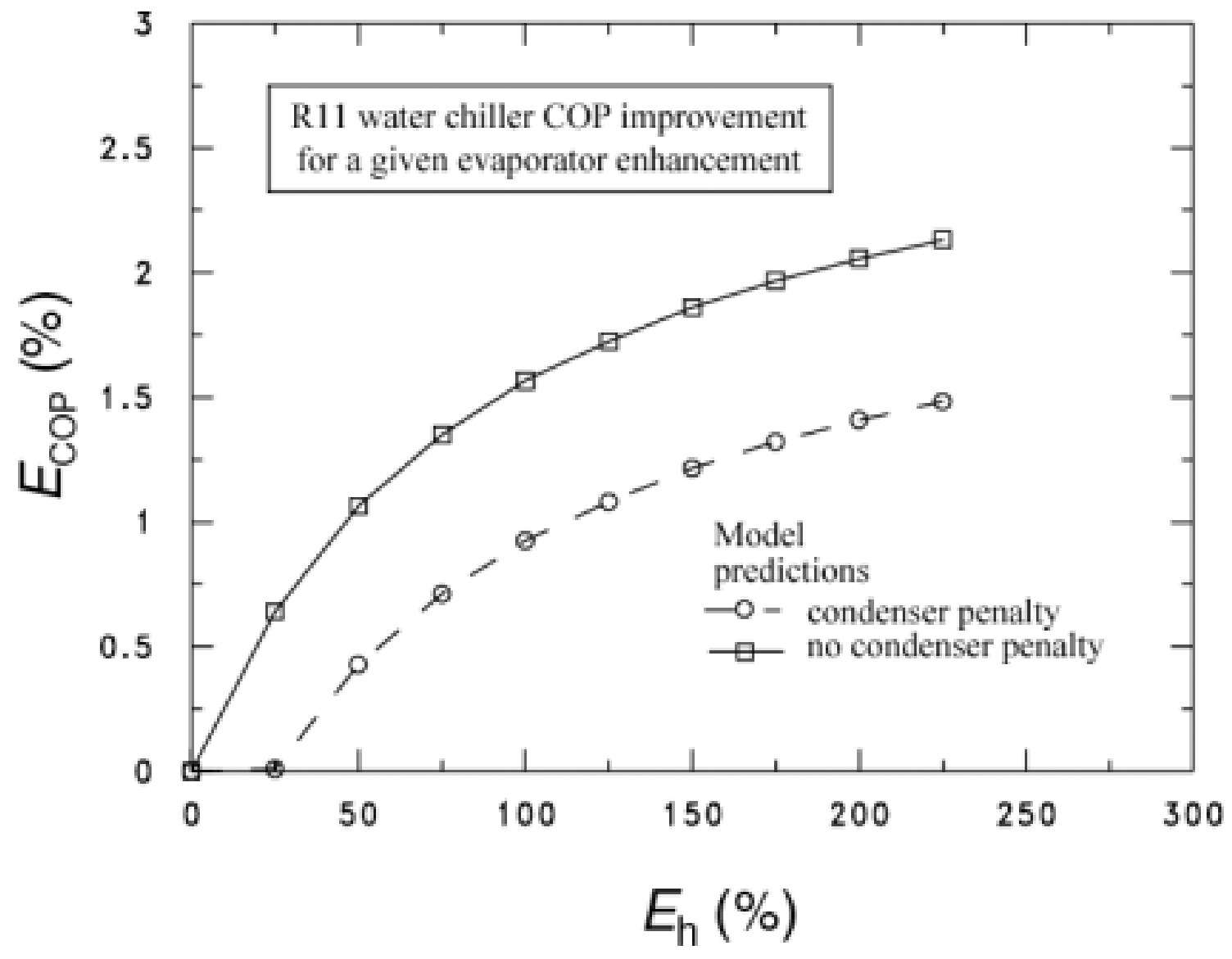

Fig. A.2 R11 water chiller COP improvement for a given evaporator enhancement 


\section{APPENDIX B: UNCERTAINTIES}

Figure B.1 shows the relative (percent) uncertainty of the heat flux $\left(U_{\mathrm{q}}\right)$ as a function of the heat flux. Figure B.2 shows the uncertainty of the wall temperature as a function of heat flux. The uncertainties shown in Figs. B.1 and B.2 are "within-run uncertainties." These do not include the uncertainties due to "between-run effects" or differences observed between tests taken on different days. The "within-run uncertainties" include only the random effects and uncertainties associated with one particular test. All other uncertainties reported in this study are "between-run uncertainties" which include all random effects such as surface past history or seeding.

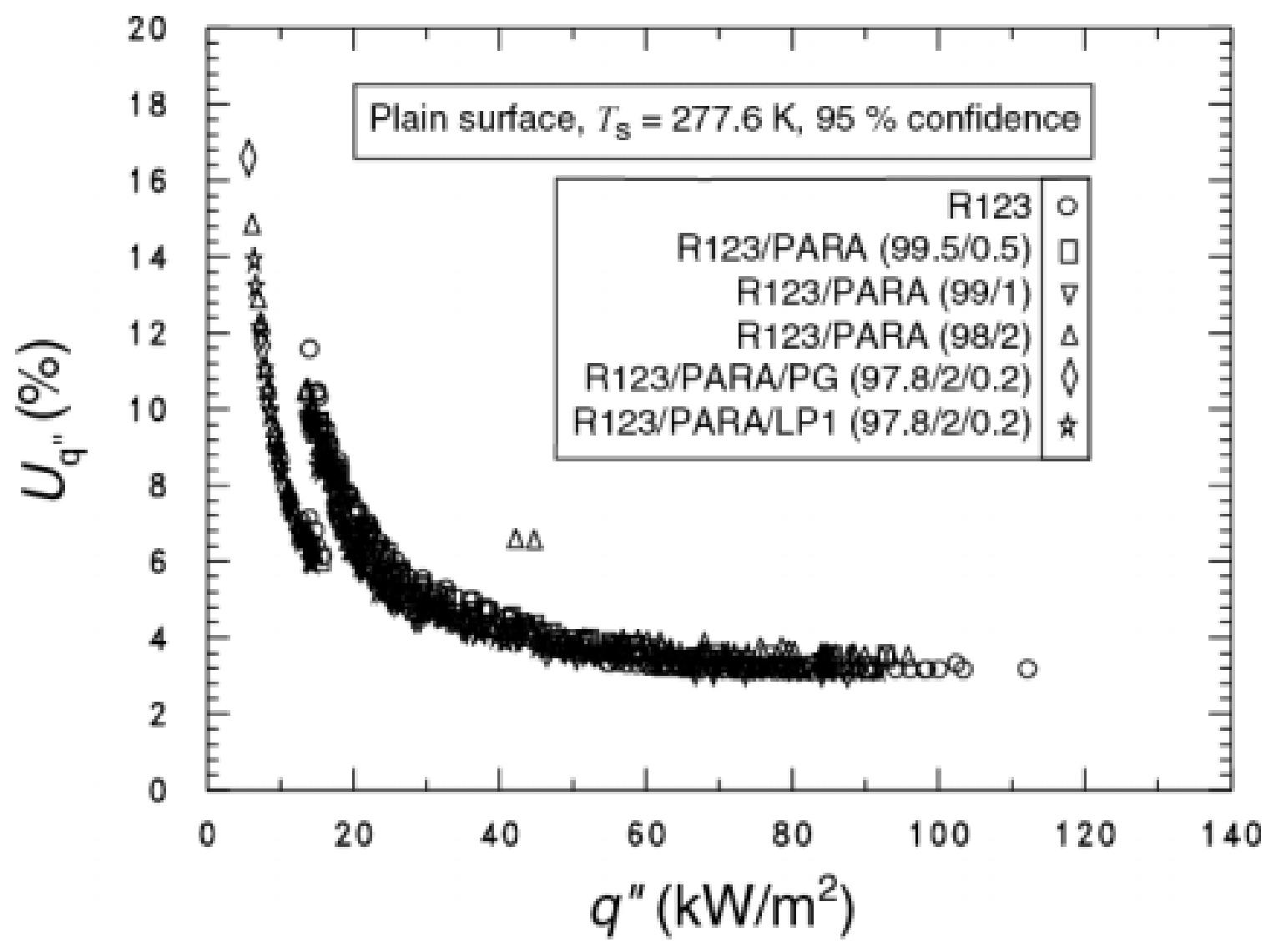

Fig. B.1 Expanded relative uncertainty in the heat flux of the surface at the $95 \%$ confidence level 


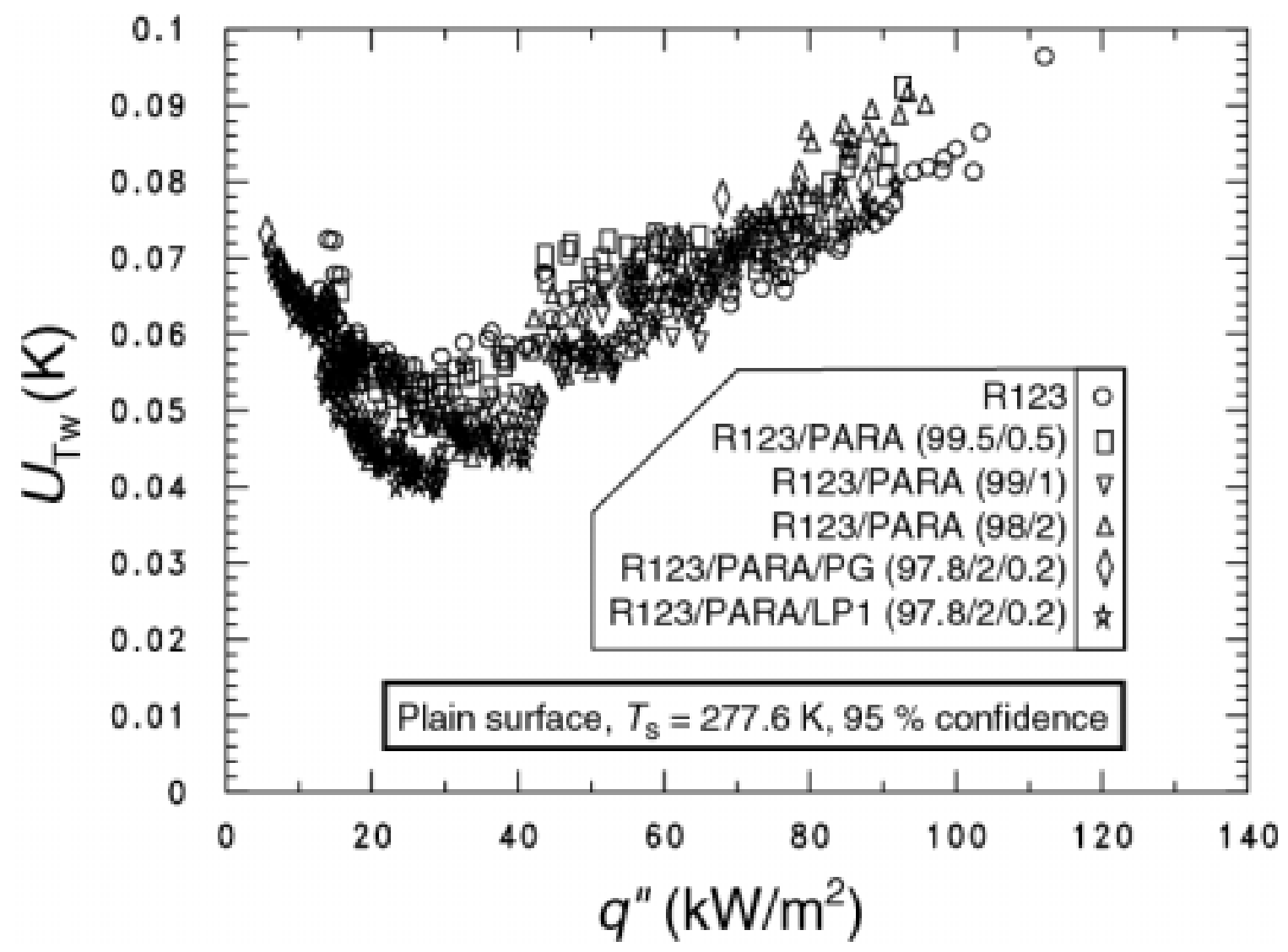

Fig. B.2 Expanded uncertainty in the temperature of the surface at the $95 \%$ confidence level 


\section{APPENDIX C: LUBRICANT LIQUID DENSITY MEASUREMENTS}

This appendix presents the measurements and the correlation of the PARA, PG, and LP1 lubricant liquid densities $\left(\rho_{1}\right)$. The density of the liquid lubricant was measured as a function of temperature with a glass pycnometer. The pycnometer was factory instrumented with a glass mercury thermometer with a range of $14^{\circ} \mathrm{C}$ to $38^{\circ} \mathrm{C}$ in $0.2^{\circ}$ graduations, accurate to within $\pm 0.2 \mathrm{~K}$. The pycnometer was filled with distilled water and its volume was calculated from the known density of water. The volume was found with 29 trails to be $9.588 \mathrm{ml}$ with a standard uncertainty of $0.002 \mathrm{ml}$. The average mass of the pycnometer after nine trials was $28.794 \mathrm{~g} \pm 0.001 \mathrm{~g}$.

The pycnometer containing the test lubricant was cooled in an ice bath and then removed from the bath and allowed to warm on the balance to room temperature over approximately one hour. The standard uncertainty of the balance was approximately $1 \mathrm{mg}$. The outside of the pycnometer was wiped clean before each measurement to remove the lubricant that was expelled through the pipette due to volume expansion with temperature increase.

The Biot number for the warming pycnometer was estimated to be approximately 0.5 , which is greater than the recommended limit of 0.1 (Incropera and Dewitt, 1985) for a uniform temperature in fluid. It is difficult to estimate the error introduced in the measurements due to temperature gradients that existed in the lubricant. However, the data regression shows that the residuals are independent of temperature, which suggests that the error due to temperature gradients in the liquid had a negligible effect on the density measurements.

Tables C.1 through C. 3 shows the recorded measurements for the three test lubricants. Equation C.1 gives the fit of the liquid lubricant density $\left(\rho_{1}\right)$ in $\mathrm{kg} / \mathrm{m}^{3}$ versus temperature $(T)$ in Kelvin:

$$
\rho_{l}=a_{0}-a_{1} T
$$

Where the coefficients for each lubricant are given in Table C.4. The expanded uncertainty of the fits were approximately $\pm 1 \mathrm{~kg} / \mathrm{m}^{3}$ for $95 \%$ confidence. 
Table C.1 PARA liquid density measurements

\begin{tabular}{|c|c|c|}
\hline$T\left({ }^{\circ} \mathrm{C}\right)$ & Lubricant mass $(\mathrm{g})$ & $\rho_{1}\left(\mathrm{~kg} / \mathrm{m}^{3}\right)$ \\
\hline 14.6 & 8.466 & 882.96 \\
\hline 17.2 & 8.449 & 881.19 \\
\hline 18 & 8.446 & 880.88 \\
\hline 19 & 8.441 & 880.36 \\
\hline 20.2 & 8.436 & 879.83 \\
\hline 21.4 & 8.428 & 879.00 \\
\hline 22 & 8.424 & 878.58 \\
\hline 22.8 & 8.418 & 877.96 \\
\hline 23.6 & 8.414 & 877.54 \\
\hline 24.2 & 8.411 & 877.23 \\
\hline 15.2 & 8.452 & 881.50 \\
\hline 18.2 & 8.442 & 880.46 \\
\hline 19.2 & 8.439 & 880.15 \\
\hline 20.4 & 8.433 & 879.52 \\
\hline 21 & 8.429 & 879.10 \\
\hline 21.8 & 8.426 & 878.79 \\
\hline 22.6 & 8.419 & 878.06 \\
\hline 23.2 & 8.417 & 877.85 \\
\hline 24 & 8.411 & 877.23 \\
\hline 14.8 & 8.453 & 881.61 \\
\hline 17.6 & 8.447 & 880.98 \\
\hline 18.6 & 8.441 & 880.36 \\
\hline 19.8 & 8.435 & 879.73 \\
\hline 20.8 & 8.429 & 879.10 \\
\hline 21.8 & 8.422 & 878.37 \\
\hline & & \\
\hline & & \\
\hline
\end{tabular}

Table C.2 PG liquid density measurements

\begin{tabular}{|c|c|c|}
\hline$T\left({ }^{\circ} \mathrm{C}\right)$ & Lubricant mass $(\mathrm{g})$ & $\rho_{\mathrm{l}}\left(\mathrm{kg} / \mathrm{m}^{3}\right)$ \\
\hline 14.2 & 9.609 & 997.38 \\
\hline 15.8 & 9.604 & 996.44 \\
\hline 16.8 & 9.595 & 995.71 \\
\hline 17.8 & 9.589 & 995.29 \\
\hline 18.8 & 9.585 & 994.77 \\
\hline 19.8 & 9.573 & 994.36 \\
\hline 20.8 & 9.567 & 993.73 \\
\hline 21.8 & 9.56 & 993.21 \\
\hline 22.8 & 9.553 & 997.48 \\
\hline 23.6 & 9.549 & 996.96 \\
\hline 24.2 & 9.543 & 996.34 \\
\hline 14.6 & 9.599 & 995.82 \\
\hline 16.8 & 9.592 & 995.40 \\
\hline 18 & 9.59 & 994.98 \\
\hline 18.8 & 9.584 & 994.25 \\
\hline 19.6 & 9.579 & 993.73 \\
\hline 20.4 & 9.575 & 993.10 \\
\hline
\end{tabular}




\begin{tabular}{|c|c|c|}
\hline 21.2 & 9.571 & 997.38 \\
\hline 21.8 & 9.567 & 996.96 \\
\hline 22.4 & 9.56 & 996.44 \\
\hline 23.2 & 9.556 & 995.82 \\
\hline 24.2 & 9.548 & 995.19 \\
\hline 15 & 9.6 & 994.77 \\
\hline 16 & 9.595 & 994.36 \\
\hline 18.2 & 9.588 & 993.63 \\
\hline 19.2 & 9.581 & 993.10 \\
\hline 20 & 9.578 & 997.38 \\
\hline 21 & 9.572 & 996.44 \\
\hline 21.8 & 9.566 & 995.71 \\
\hline 22.8 & 9.559 & 995.29 \\
\hline 23.6 & 9.552 & 994.77 \\
\hline 24.4 & 9.55 & 994.36 \\
\hline 14 & 9.618 & 993.73 \\
\hline 15 & 9.611 & 993.21 \\
\hline 15.8 & 9.602 & 997.48 \\
\hline 16.6 & 9.595 & 996.96 \\
\hline 17.4 & 9.591 & 996.34 \\
\hline 18.2 & 9.584 & 995.82 \\
\hline 19.4 & 9.578 & 995.40 \\
\hline 20.4 & 9.571 & 994.98 \\
\hline 21.2 & 9.566 & 994.25 \\
\hline 22 & 9.562 & 993.73 \\
\hline 23 & 9.554 & 993.10 \\
\hline 24 & 9.55 & 997.38 \\
\hline 24.6 & 9.544 & 996.96 \\
\hline
\end{tabular}


Table C.3 LP1 Liquid Density Measurements

\begin{tabular}{|c|c|c|}
\hline$T\left({ }^{\circ} \mathrm{C}\right)$ & Lubricant mass (g) & $\rho_{1}\left(\mathrm{~kg} / \mathrm{m}^{3}\right)$ \\
\hline 14.2 & 8.89 & 927.19 \\
\hline 16.4 & 8.88 & 926.15 \\
\hline 17.2 & 8.871 & 925.21 \\
\hline 17.6 & 8.866 & 924.69 \\
\hline 18 & 8.86 & 924.06 \\
\hline 18.8 & 8.854 & 923.43 \\
\hline 19.8 & 8.849 & 922.91 \\
\hline 21.4 & 8.841 & 922.08 \\
\hline 22 & 8.838 & 921.77 \\
\hline 22.6 & 8.832 & 921.14 \\
\hline 23.4 & 8.828 & 920.72 \\
\hline 24.2 & 8.822 & 920.10 \\
\hline 15.2 & 8.875 & 925.62 \\
\hline 16.2 & 8.87 & 925.10 \\
\hline 16.8 & 8.866 & 924.69 \\
\hline 17.8 & 8.862 & 924.27 \\
\hline 19 & 8.853 & 923.33 \\
\hline 19.6 & 8.848 & 922.81 \\
\hline 20.4 & 8.846 & 922.61 \\
\hline 21.6 & 8.836 & 921.56 \\
\hline 22.6 & 8.833 & 921.24 \\
\hline 23.4 & 8.828 & 920.72 \\
\hline 24.2 & 8.823 & 920.20 \\
\hline 14.4 & 8.873 & 925.42 \\
\hline 15.6 & 8.868 & 924.89 \\
\hline 16.6 & 8.866 & 924.69 \\
\hline 17.6 & 8.859 & 923.96 \\
\hline 18.4 & 8.853 & 923.33 \\
\hline 19.4 & 8.848 & 922.81 \\
\hline 20.4 & 8.842 & 922.18 \\
\hline 21.6 & 8.835 & 921.45 \\
\hline 22.4 & 8.831 & 921.04 \\
\hline 23.4 & 8.825 & 920.41 \\
\hline 24.2 & 8.822 & 920.10 \\
\hline
\end{tabular}


Table C.4 Density coefficients for eq. C.1

\begin{tabular}{|c|c|c|}
\hline Lubricant & $\mathrm{a}_{0}\left(\mathrm{~kg} / \mathrm{m}^{3}\right)$ & $\mathrm{a}_{1}\left(\mathrm{~kg} \mathrm{~m}^{-3} \mathrm{~K}^{-1}\right)$ \\
\hline $\begin{array}{c}\text { Paraffinic } \\
\text { Mineral oil } \\
\text { (PARA) }\end{array}$ & 1038.76 & -0.5431 \\
\hline $\begin{array}{c}\text { DGLF118 } \\
\text { (PG) }\end{array}$ & 1189.67 & -0.6519 \\
\hline LP1 & 1107.84 & -0.6314 \\
\hline
\end{tabular}




\section{APPENDIX D: CAPILLARY RISE MEASUREMENTS}

This appendix presents capillary rise measurements for PARA, PG and LP1 at approximately $25^{\circ} \mathrm{C}$. Tables D.1 through D. 3 provide the capillary rise height measurements $(l)$ that were used to calculate the surface tension for the lubricant and the additive. The first column for each fluid gives the height of the liquid in the tube after it had been removed from the liquid pool while placing a finger over the tube opening. The second column for each liquid gives the rise height by subtracting off the height of the pool $(d)$ from the first column measurements. The standard deviation of the mean measurement for this method was approximately $0.5 \%$ of the measurement. The pool height was kept small so that if a $100 \%$ error had occurred in the measurement of the pool depth it would contribute only approximately $10 \%$ to the measurement of the capillary rise-height.

A force balance on the column of liquid in the capillary tube was used to calculate the surface tension (Adamson and Gast, 1997):

$$
\sigma=\frac{r \Delta \rho g l}{2} \approx \frac{r \rho_{l} g l}{2}
$$

where the measured radius of the capillary tube $(r)$ was $0.97 \mathrm{~mm}$ with a B-type estimated uncertainty of $\pm 0.03 \mathrm{~mm}$. The liquid densities $\left(\rho_{1}\right)$ measurements are given in Appendix C. The uncertainty of the density measurements is approximately $\pm 1 \mathrm{~kg} / \mathrm{m}^{3}$.

The liquid-vapor (air) surface tensions as calculated from eq (D.1) for the PARA, PG and LP1 were $0.0306 \mathrm{~N} / \mathrm{m} \pm 0.0007 \mathrm{~N} / \mathrm{m}, 0.0322 \mathrm{~N} / \mathrm{m} \pm 0.0007 \mathrm{~N} / \mathrm{m}$ and, $0.0317 \mathrm{~N} / \mathrm{m} \pm$ $0.0007 \mathrm{~N} / \mathrm{m}$, respectively. 
Table D.1 Capillary rise measurements for LP1

\begin{tabular}{|c|c|c|c|c|}
\hline$T\left({ }^{\circ} \mathrm{C}\right)$ & $h+d(\mathrm{~mm})$ & $h(\mathrm{~mm})$ & $\rho\left(\mathrm{kg} \mathrm{m}^{-3}\right)$ & $\sigma\left(\mathrm{N} \mathrm{m}^{-1}\right)$ \\
\hline 24.73 & 29 & 27 & 919.75 & 0.03171 \\
\hline 24.73 & 29 & 27 & 919.75 & 0.03171 \\
\hline 24.73 & 29 & 27 & 919.75 & 0.03171 \\
\hline 24.72 & 29 & 27 & 919.75 & 0.03171 \\
\hline 24.71 & 29 & 27 & 919.76 & 0.03171 \\
\hline 24.63 & 29 & 27 & 919.81 & 0.03171 \\
\hline
\end{tabular}

Table D.2 Capillary rise measurements for PG

\begin{tabular}{|c|c|c|c|c|}
\hline$T\left({ }^{\circ} \mathrm{C}\right)$ & $h+d(\mathrm{~mm})$ & $h(\mathrm{~mm})$ & $\rho\left(\mathrm{kg} \mathrm{m}^{-3}\right)$ & $\sigma\left(\mathrm{N} \mathrm{m}^{-1}\right)$ \\
\hline 24.42 & 64 & 26 & 995.68 & 0.03306 \\
\hline 24.402 & 63.5 & 25.5 & 995.69 & 0.03242 \\
\hline 24.39 & 63.5 & 25.5 & 995.70 & 0.03242 \\
\hline 24.37 & 63.5 & 25.5 & 995.71 & 0.03242 \\
\hline 24.35 & 63.5 & 25.5 & 995.72 & 0.03242 \\
\hline 24.33 & 63.5 & 25.5 & 995.73 & 0.03242 \\
\hline 24.40 & 63.5 & 25.5 & 995.69 & 0.03242 \\
\hline 24.40 & 63.5 & 25.5 & 995.69 & 0.03242 \\
\hline 24.38 & 60.5 & 25.5 & 995.70 & 0.03242 \\
\hline 24.37 & 60.5 & 25.5 & 995.71 & 0.03242 \\
\hline 24.36 & 60.5 & 25.5 & 995.72 & 0.03242 \\
\hline 24.24 & 60.5 & 25.5 & 995.79 & 0.03242 \\
\hline 24.88 & 60.5 & 25.5 & 995.37 & 0.03241 \\
\hline 24.89 & 48 & 25 & 995.37 & 0.03177 \\
\hline 24.89 & 48.5 & 25.5 & 995.37 & 0.03241 \\
\hline 24.83 & 48 & 25 & 995.411 & 0.03178 \\
\hline 24.82 & 48 & 25 & 995.41 & 0.03178 \\
\hline 24.62 & 48 & 25 & 995.54 & 0.03178 \\
\hline 24.08 & 38 & 25 & 995.91 & 0.03179 \\
\hline 24.09 & 38 & 25 & 995.89 & 0.03179 \\
\hline
\end{tabular}

Table D.3 Capillary rise measurements for PARA

\begin{tabular}{|c|c|c|c|c|}
\hline$T\left({ }^{\circ} \mathrm{C}\right)$ & $h+d(\mathrm{~mm})$ & $h(\mathrm{~mm})$ & $\rho\left(\mathrm{kg} \mathrm{m}^{-3}\right)$ & $\sigma\left(\mathrm{N} \mathrm{m}^{-1}\right)$ \\
\hline 24.63 & 63.5 & 27.5 & 877.03 & 0.03080 \\
\hline 24.62 & 63.5 & 27.5 & 877.04 & 0.03080 \\
\hline 24.61 & 63.5 & 27.5 & 877.04 & 0.03080 \\
\hline 24.60 & 63.5 & 27.5 & 877.05 & 0.03080 \\
\hline 24.60 & 63.5 & 27 & 877.05 & 0.03024 \\
\hline 24.56 & 63.5 & 27 & 877.07 & 0.03024 \\
\hline 24.47 & 63.5 & 27 & 877.12 & 0.03024 \\
\hline 24.46 & 56 & 27.5 & 877.13 & 0.03080 \\
\hline
\end{tabular}




\section{APPENDIX E: LUBRICANT VISCOSITY MEASUREMENTS}

This appendix presents the liquid kinematic viscosity measurements for PARA, PG and LP1 at approximately $25^{\circ} \mathrm{C}$ in Tables E.1 through E.3. Glass viscometers at the appropriate viscosity range were used to measure the viscosities of each lubricant. The B-type uncertainty of the viscometer was quoted by the manufacturer as $0.22 \%$ of the measurement for the PARA lubricant and $0.29 \%$ of the measurement for the PG lubricant for a $95 \%$ confidence level. The average measured viscosity of the PARA, and PG lubricants, for the $95 \%$ confidence level, was $85 \mu \mathrm{m}^{2} / \mathrm{s} \pm 1.5 \mu \mathrm{m}^{2} / \mathrm{s}$, and $150.3 \mu \mathrm{m}^{2} / \mathrm{s} \pm 0.8 \mu \mathrm{m}^{2} / \mathrm{s}$, respectively. Only a single viscosity measurement of approximately $3800 \mu \mathrm{m}^{2} / \mathrm{s}$ was made for the LP1 lubricant because of its extremely large viscosity requiring over four hours. As a result, the viscosity quoted by the manufacturer on the MSDS of $2000 \mu \mathrm{m}^{2} / \mathrm{s}$ was taken as the value for LP1.

A model 300 viscometer with a viscosity range of $50 \mu \mathrm{m}^{2} / \mathrm{s}$ to $250 \mu \mathrm{m}^{2} / \mathrm{s}$ was used. The calibration constant $\left(C_{\mathrm{o}}\right)$ for the viscosity was a function of viscometer/liquid temperature:

$$
C_{o}=0.24317-1.6667 \times 10^{-5} T
$$

where $T$ is in Celsius and $C_{\mathrm{o}}$ is in $\mu \mathrm{m}^{2} / \mathrm{s}$.

The kinematic viscosity in $\mu \mathrm{m}^{2} / \mathrm{s}$ was obtained by multiplying the measured efflux time in seconds by $C_{\mathrm{o}}$.

Table E.1 Kinematic viscosity measurements for PARA

\begin{tabular}{|c|c|c|c|}
\hline$T\left({ }^{\circ} \mathrm{C}\right)$ & Efflux time $(\mathrm{s})$ & $C_{\mathrm{o}}\left(\mu \mathrm{m}^{2} / \mathrm{s}\right)$ & $\nu\left(\mu \mathrm{m}^{2} / \mathrm{s}\right)$ \\
\hline 24.648 & 349.55 & 0.242755867 & 84.85 \\
\hline 24.655 & 346.65 & 0.24275575 & 84.15 \\
\hline 24.645 & 352.05 & 0.242755917 & 85.46 \\
\hline 24.637 & 352.4 & 0.24275605 & 85.54 \\
\hline 24.635 & 352.1 & 0.242756083 & 85.47 \\
\hline 24.629 & 353.59 & 0.242756183 & 85.83 \\
\hline
\end{tabular}

Table E.2 Kinematic viscosity measurements for PG

\begin{tabular}{|c|c|c|c|}
\hline$T\left({ }^{\circ} \mathrm{C}\right)$ & Efflux time $(\mathrm{s})$ & $C_{\mathrm{o}}\left(\mu \mathrm{m}^{2} / \mathrm{s}\right)$ & $\nu\left(\mu \mathrm{m}^{2} / \mathrm{s}\right)$ \\
\hline 24.579 & 617.59 & 0.242757017 & 149.92 \\
\hline 24.586 & 599.82 & 0.2427569 & 145.61 \\
\hline 24.569 & 618.36 & 0.242757183 & 150.11 \\
\hline 24.562 & 620.5 & 0.2427573 & 150.63 \\
\hline 24.554 & 620.78 & 0.242757433 & 150.69 \\
\hline 24.545 & 619.61 & 0.242757583 & 150.41 \\
\hline
\end{tabular}

Table E.3 Kinematic viscosity measurements for LP1

\begin{tabular}{|c|c|c|c|}
\hline$T\left({ }^{\circ} \mathrm{C}\right)$ & Efflux time $(\mathrm{s})$ & $C_{\mathrm{o}}\left(\mu \mathrm{m}^{2} / \mathrm{s}\right)$ & $\nu\left(\mu \mathrm{m}^{2} / \mathrm{s}\right)$ \\
\hline 24.81 & 15633.25 & 0.242753167 & 3795. \\
\hline
\end{tabular}

